\title{
Regime Stability and the Persistence of Traditional Practices*
}

\author{
Michael Poyker ${ }^{\dagger}$
}

June 4, 2021

\begin{abstract}
This paper investigates the role of national institutions on the persistence of cultural norms and traditions. In particular, I examine why the harmful tradition of female genital mutilation persists in certain African countries while in others it has been eradicated. I argue that people are more willing to abandon their cultural norms and traditions if they are confident that the government is durable enough to set up longterm replacements for them. I exploit the fact that ethnic groups in Africa were artificially partitioned by national borders and, using a country-ethnicity panel dataset spanning 23 countries from 1970 to 2013, I show that a one-standard-deviation larger increase in political regime durability leads to a 0.1-standard-deviation larger decline in the share of newly-circumcised women, conditional on the presence of an anti-FGM government policy.
\end{abstract}

JEL Codes: D19, J15, O12, Z13

Keywords: Traditional Practices, Female Genital Mutilation, Regime Durability

${ }^{*}$ The author is grateful to Maxim Ananyev, Sascha O. Becker, Marc F. Bellemare, Lisa Blaydes, Kirill Borusyak, Matt Collin, Christian Dippel, Stefano Fiorin, Paola Giuliano, Vasily Korovkin, Yuya Kudo, Egor Lazarev, Adriana Lleras-Muney, Gerry Mackie, Bruno Pellegrino, Konstantin Platonov, Daniel Posner, Imran Rasul, Vera Sharunova, Michelle Tertilt, Yuan Tian, Nico Voigtländer, Till von Wachter, Romain Wacziarg, David Yanagizawa-Drott, Noam Yuchtman, seminar participants at UCLA, and conference participants at APSA, ASREC, COMPASS, CSAE, IRES, MPSA, SIOE, Stanford-AALIMS, and UC GEM-BPP for excellent suggestions. I thank Bernard Barrère for providing Mauritania DHS data. All errors are mine. Correspondence at: Sir Clive Granger Building B33, School of Economics, University of Nottingham, University Park, NG7 2RD, Nottingham, UK.

†Poyker: University of Nottingham; e-mail address: mikhail.poyker@nottingham.ac.uk 
Why are some harmful, supposedly outdated cultural traditions still practiced, while others have been eradicated? For instance, footbinding in China has been abolished, while female genital mutilation (FGM) and the wearing of neck rings are still widely practiced in many developing countries. Cultural practices arise because people find them beneficial at certain times and in certain contexts (e.g., footbinding and FGM aiding the marriage market). Over time, these practices become deeply held traditional values and religious beliefs (Gigerenzer, 2007; Kahneman, 2011), even when the context has changed. A society may dispose of these norms if the cost of practicing the old traditions under the new circumstances outweigh the benefits. This process can be difficult, since the change of social norms requires coordination of members of the practicing community. One factor can be especially important in solving this coordination problem: expectations about the life expectancy of political regimes that support changes in a certain norm. Understanding how to hasten abolishment of these norms is important for development, given their potential harmful effects on health, education, and quality of life. ${ }^{1}$

In this paper, I investigate the role of political regime durability on the persistence and decay of FGM in Africa. FGM is a cultural norm that requires girls to be circumcised at some point during childhood, and circumcised girls are more likely to find a husband on the marriage market (Mackie, 1996). Currently, more than 150 million girls and women living in 29 countries have been circumcised. Because FGM is harmful for

\footnotetext{
${ }^{1}$ In addition to FGM, many other harmful traditions are still being practiced, including the cultural preferences for sons rather than daughters, female infanticide, early marriage, force-feeding, nutritional taboos, wearing of lip plates, practices related to birthing, and the use of traditional medicines and witch doctors. We can also interpret traditional practices as tribal or religious social norms practiced by society. Even if they are not harmful per se, if one region of a country starts to follow its traditional laws rather than the official national system, this can impede the country's wider economic development and lower the quality of its domestic institutions (Tabellini, 2008).
} 
women's health, governments try to implement anti-FGM campaigns to eradicate this practice. Due to the coordination problem, the government needs to "simultaneously shift the expectations of a group of interacting families, so that it would become rational for them not to continue the practice given its harmful effects and its decreased benefit in the local marriage market" (Young, 2015). Girls are circumcised when they are young, but the marriage market happens in the future. Hence, if a mother wants not to circumcise her daughter, she needs to be sure that the political regime that pushes for the eradication of FGM will still be doing so by the time of the marriage market for her to be able to marry her daughter without FGM. Thus, what really matters is the expectation about how long the political regime that pushes for eradication of FGM will last.

I use the Demographic and Health Survey and the Multiple Indicator Cluster Survey (hereafter, DHS and MICS) individual-level datasets for countries where FGM has ever been practiced. I construct a country-ethnicity-year panel of the share of newly circumcised women from the total number of women whose age makes them eligible for circumcision as the measure of FGM prevalence. I measure regime durability using the Polity IV (Marshall and Cole, 2013) dataset, which counts the number of years since the last significant changes in authority characteristics. I find that ethnic groups that are exposed to higher regime durability experience lower rates of FGM, and the effect is driven by countries with anti-FGM legislations. The results are robust to using different geographic aggregations and not driven by subsamples.

My identification relies on the fact that FGM is an ethnic-group-specific cultural norm, and that ethnic partition of African ethnolinguistic groups by state borders defined by colonial authorities provides random variation within ethnicity (similar to Alesina, East- 
erly and Matuszeski, 2011, Michalopoulos and Papaioannou, 2014, 2018, Michalopoulos, Naghavi and Prarolo, 2018 and Michalopoulos, Putterman and Weil, 2019). In other words, I observe the same ethnic group under political regimes with different durability. For example, the Dagari ethnic group was artificially divided between Burkina Faso and Ghana by the colonial administration. Despite the similarity in these countries' socioeconomic characteristics, FGM rates differ significantly between the two sides of the border: 87 percent in Burkina Faso vs. 51 percent in Ghana. ${ }^{2}$ In addition, in DHS samples that have information on mothers' circumcised and uncircumcised daughters and their FGM age, I can explore how a woman chooses whether to circumcise her daughters under different values of regime durability throughout her lifetime.

Key to my analysis is whether the measurement of regime durability is a good proxy for people's expectation of future regime stability. I demonstrate this in three ways. First, I show that my results hold if instead of the Polity IV measure of regime durability I use alternative indicators (or their first-principal component). These indicators are based on different measures of policy scores that take into account different institutional factors. While not perfectly correlated, all of them yield similar estimates. Second, I show that my results are not driven by regime changes without polity score changes (e.g., change of an autocrat without change in authority characteristics). Third, I show that my measure of regime durability correlates with people's expectations that the government will solve their local problems within the next five years, using survey information in Afrobarometer. My results are robust to alternative coding of anti-FGM policy. I find that the effect is

\footnotetext{
${ }^{2}$ Similarly, many other ethnic groups separated by national borders evince different rates of FGM prevalence (Figure D.1).
} 
driven by (i) countries that have a clear definition of FGM in their legislation, (ii) countries that criminalized (with imprisonment) performance of FGM, or (iii) governments that announced a strategy in place to end FGM. Results are similar if I use continuous measures based on the number of these laws or first-principal component of the anti-FGM laws.

There are two important omitted-variable concerns. First, other country-year specific institutional factors may confound the effect of regime stability. For example, if regime durability is positively correlated with state capacity and the latter is negatively correlated with FGM rates through education, omitting state capacity can bias the result. I show that controlling for these institutional variables leaves the estimated effect of regime durability virtually unchanged. Second, regime durability may correlate with NGO activities and governmental health programs. Thus, the effect of interest may be explained by NGOs being more active in countries with more stable political regimes. Similarly, a more durable political regime can attract more foreign aid and then more successfully fight FGM. I demonstrate that neither foreign aid nor the number of active NGOs affects the magnitude or significance of my results.

I also investigate several alternative explanations. First, more durable regimes may be better at improving health outcomes, which are not necessarily related to expectations and coordination problems. I find no effects of regime durability on other health-related outcomes such as infant mortality, HIV prevalence, fertility, life expectancy, medical provision, or government attempts to empower women. Second, I show that regime durability does not correlate with ethnic or religious identity. Finally, my results may capture the fact that women are afraid of being prosecuted by a stable regime that is trying to eradicate FGM and they underreport their FGM status. To address this concern, I use 
information from Afrobarometer where respondents are asked about whether they are afraid of openly saying that they are ready to violate the law. I find that my results hold in the subsample of countries where people are more open to answer "No" to this question, who probably also would not lie about whether they are circumcised.

The effect of regime stability goes beyond FGM; it holds for other cultural norms being targeted for systematic eradication. To the best of my knowledge, the only cultural norms with available data are child marriage, a practice wildly targeted by governmental organizations (Wang, 2016), and polygamy, a practice where national bans and other policies have been mostly ineffective (Fenske, 2015). Child marriage is similar to FGM in the sense that expectations about future anti-cultural-norm policies matter: daughters should be married while young, and by postponing marriage, families risk not finding a good husband. On the other hand, polygamy does not rely on expectations about how the regime will fight against the practice in the future. Consistent with the hypothesis, I find a negative and significant relationship between child marriages and regime durability, of a similar magnitude to the FGM results, and no significant effect on polygamy.

This paper makes several contributions to the literature. First is the literature on the existence and evolution of social norms (Ellickson, 1989, 1991, North, 1990, Bisin, Topa and Verdier, 2009, and Bisin et al., 2011). Mostly relatedly, Fan and Wu (2018) argue that footbinding in China appeared first in the upper social class and then spread through the society since women wanted to marry up. Becker (2018) presents evidence on how FGM appeared in Africa where men wanted to make sure that wives were loyal to them when they were hunting. Young (2015) provides a theory on how footbinding was abolished and FGM persisted in the context of a coordination problem. While consistent with the 
origin stories and the theory with coordination issue, I explain how the formal institutions and government policies help in generating coordinated efforts to abolish harmful practices such as FGM.

Second, the paper contributes to the literature on impacts of institutional changes on social and economic outcomes (Bisin and Verdier, 2000, 2001, Alesina and Giuliano, 2015, García-Jimeno (2016), and Giuliano and Nunn, 2017). The literature has discussed the role of prohibition laws, state capacity, slavery, and ancestral political autonomy. Here I show that a particular institutional feature, regime durability, affects cultural norms by helping to solve the coordination problem through changes in people's expectations.

Third, this paper adds to the literature on the particular issue of FGM (Mackie, 2003, Efferson et al., 2015, and Vogt et al., 2016). One part of the literature focuses on the impact of FGM on various individual outcomes including health, education, and productivity (Shell-Duncan, 2001, 2008, Mackie, 2003). Another set discusses the effect of laws and anti-FGM program on the eradication of the practice (Shell-Duncan and Herniund, 2007, Shell-Duncan et al., 2011). Instead of focusing on one country or one program, my paper shows that a country-level variable, regime durability, significantly affects the effectiveness of the policies, since people need the policies to be in place for long enough to be able to commit to deviate from the norm.

Finally, this paper complements the work on African development in general. While I don't show the direct impact of institutions on long-term health and economic outcomes, given the individual evidence in the literature on the harmful effect of out-dated cultural practices, my results suggest that stable regime are likely to promote economic growth in the long run. 


\section{FGM: Historical Background and Conceptual Framework}

In this section, I first provide historical facts about FGM and formulate hypotheses about its persistence. Then I discuss governmental policies related to its abolishment. Finally, I provide several pieces of factual records on how expectations regarding antiFGM policies affect the way people decide about circumcision.

\subsection{The Historical Origins and Persistence of FGM}

FGM is a tradition in some western, eastern, and northeastern regions of Africa (Figure D.2), and some countries in the Middle East (e.g., Iraq and Yemen, UNICEF, 2013). According to the World Health Organization, more than 150 million girls and women have been circumcised, and another 30 million are estimated to be at risk of circumcision over the next decade. The circumcision of girls is part of the system of indigenous beliefs of the ethnic groups who practice it. The first recorded instance of FGM was 2,200 years ago in the territory now recognized as Northern Sudan. After the Arab Caliphate was established, Sudanese sex slaves (who underwent circumcision) were transferred via trade routes (Beachey, 1976), leading to the spread of the practice across Africa.

Most existing theories on the persistence of FGM and other harmful practices were developed by sociologists; they have been summarized in Hartung (1976), Mackie (1996), Mackie and LeJeune (2009), Shell-Duncan and Herniund (2007), and UNICEF (2007). Translating the basic hypotheses into the language of economics, a male's primary goal is to father as many children as possible; meanwhile, it is obvious that only the woman who is carrying a child can be sure about whether a particular child is hers or not. In this 
situation, men - especially in polygamist societies — are prepared to take costly actions (e.g., FGM or footbinding) to increase the probability that the children they support are their own. By undergoing FGM, women become less promiscuous because they lose the opportunity to enjoy sex.

Over time, FGM persisted and became a social norm (Lightfoot-Klein, 1989, Mackie, 1996, Easton, Monkman and Miles, 2003, Hayford, 2005, Shell-Duncan and Herniund, 2007, and Young, 2015). To have a better chance of finding a good match in the marriage market, girls and women need to follow social norms; therefore, those desiring better prospects must be circumcised (Kudo, 2018). ${ }^{3}$ If a girl or woman does not follow the social norm, she risks not only worse marriage-market outcomes but also potential punishment by her kin. ${ }^{4}$ Moreover, there are sometimes direct economic benefits. For example, in Uganda, a circumcised girl will earn her family 25 more cows as a bride price than an uncircumcised girl (Weber, 2012).

Better marriage-market outcomes come at the cost of severe health consequences for circumcised girls. FGM is harmful to the physical and psychological well-being of women and also worsens the health of their children, even when it is performed by doctors. ${ }^{5}$ It is documented that the circumcision procedure can lead to death due to bad sanitary and surgical conditions and blood loss. In the few months following the procedure, women

\footnotetext{
${ }^{3}$ For example, Wagner (2015) shows that, in a sample of 13 countries, women who had undergone genital circumcision were on average 40 percent more likely to get married.

${ }^{4}$ In some ethnic groups in Guinea-Bissau, uncircumcised women are not considered clean enough to prepare food, and are thus ostracized by fellow villagers; in Uganda, they are often accused of witchcraft (Weber, 2012; Orchid Project, 2013). Howard and Gibson (2017) show how there may be real benefits in terms of reproductive outcomes in conforming to the group norms on FGM.

${ }^{5}$ Details of FGM-related health issues can be found in Koso-Thomas, 1987, Toubia, 1994, WHO, 1998, Brady, 1999, Jones et al., 1999, Hakin, 2001, Morison et al., 2001, Shell-Duncan (2001), Elnashar and Abdelhady, 2007, Shell-Duncan and Herniund, 2007, Bjalkander et al., 2012, and Wagner, 2015.
} 
may experience severe bleeding and urination problems, which can lead to cysts, infections, and infertility in the long run. When they give birth, there are increased risks of complications and newborn deaths. Circumcised women also experience pain during intercourse, reduced sexual satisfaction, and reduced sexual desire.

Over time, people become more conscious of the value of good health in quality of life, and the cost of FGM becomes higher. However, abolishing FGM is a coordination problem; everyone in the community must choose whether to follow the social norm, based on their understanding of the health costs of FGM and their expectation of the share of people who will deviate from the practice (Schelling, 1980, Mackie, 1996, and Young, 2015). Given personal evaluations of the health costs, parents need to be strategic to secure marriages for their daughters. ${ }^{6}$ If everyone circumcises their daughters, uncircumcised girls will be worse off in the marriage market. If few people are willing to circumcise their daughters, uncircumcised girls will not lose much in the marriage market. As a result, the equilibrium will be either all girls undergo FGM or none of them do.

\subsection{Anti-FGM Policies}

African governments currently fight FGM in three ways. The first is prosecuting those who commit FGM, when such criminal legislation exists. However, this approach is not efficient, since states' willingness and ability to enforce anti-FGM laws is low, even in cases where circumcision causes death (Rahman and Toubia, 2000). The second is edu-

\footnotetext{
${ }^{6}$ In Mali, $58 \%$ of girls who have been circumcised are the daughters of mothers who think that FGM practices should be stopped. Men, too, derive less satisfaction from having sex with women who are circumcised (Boddy, 1982, Lightfoot-Klein, 1989, Makhlouf Obermeyer, 2005, and Shell-Duncan et al., 2011). In Guinea, where more than $85 \%$ of women are circumcised, only $19 \%$ of women think that FGM practice should be eliminated vs. $42 \%$ of men who think the same.
} 
cating women about their rights and about the consequences of FGM, through programs created by government agencies or international NGOs, or, infrequently, through media or billboard campaigns (UNICEF, 2007, 2008, 2013). The third and most popular one is using governmental agencies to gather commitments from as many people as possible in each village that they will not circumcise their daughters and will promise to marry their sons only to uncircumcised girls (TOSTAN, 2013; UK Department for International Development, 2013; UNFPA and UNICEF, 2013). Clearly, this approach is consistent with the hypothesis that FGM is a collective action problem. The goal of government agencies in these campaigns is to persuade a critical mass of villagers and to broadcast a signal to all villagers that their uncircumcised daughters will still have the opportunity for good marriage-market outcomes (Diop et al., 2004; Mackie and LeJeune, 2009).

Because parents decide to perform FGM on average ten years before their daughters enter the marriage market, for the last strategy to work, people should expect the anti-FGM policy to last long enough for them to succeed in the marriage market without suffering the health costs of FGM. If people believe that the anti-FGM policy will persist in the long run, long enough for their daughters to find a good spouse without undergoing FGM, then they will choose not to circumcise their daughters. This means that the regime-stability channel and the promotion of anti-FGM programs by governments can affect the decay of the tradition by altering people's expectations about future activities of government agencies.

In the unusual case where a regime is de facto in favor of such harmful practices, the effect of regime durability will be the opposite. For example, in Sierra Leone, fighting against FGM is a taboo for the political elite, and the government does not support any 
form of consistent anti-FGM policy (The Guardian, 2015). FGM is an initiation procedure here for joining the secret "Bondo society" that exists in every village and town and serves as a vital communications link between politicians and rural communities. If politicians attack FGM too enthusiastically, they run the risk of losing votes. As a result, the country's FGM rate is almost $90 \%$.

\subsection{Factual Records and Graphical Evidence}

The importance of regime stability is supported by several factual records. For example, Diop et al. (2004) show that 63 percent of people who had participated in a public commitment event felt the declaration would be respected compared with 48 percent of nonparticipants. A study by Marcus and Page (2014) provides similar figures (57\% and $44 \%$ ). When public-declaration programs operate year to year in the same villages, they become even more efficient. According to Marcus and Page (2014), longer programs (lasting six to ten years, even up to 15 years in some locations) are more successful than shorter programs. Bicchieri and Marini (2015) also document that FGM dynamics are strongly associated with social expectations. For example, Caldwell, Orubuloye and Caldwell (2000) write: "Many mothers who continue to 'circumcise' their daughters say that they would desist if only that message were much stronger, thus guaranteeing that uncircumcised girls were in the majority. They feel that it is unfair of the government to promote change without doing it very loudly and clearly." Similarly, consistent anti-FGM policy in Kenya is considered a "signal that social norms are changing, bring[ing] the subject out into the open and giv[ing] cover to parents or girls who don't want to go through it [undergone FGM]" (UNFPA, 2010).

Meanwhile, evidence exists that anti-FGM activities in certain countries are not sus- 
tained due to political instability and weakening of the country's regime (Orchid Project, 2013 and The New Republic, 2015). In such countries, people revert to their traditions. A striking example is Mali, where anti-FGM activity in numerous villages had led to a dramatic decrease in FGM rates. But, following a coup in 2012, households began to circumcise girls again. Leimbach (2014) stated that there are "side effects of the political turmoil that struck the country in 2012 and continue today, making government attempts and commitments by nonprofit groups to improve conditions for women a huge struggle." The same situation happened in Burkina Faso, where FGM rates soared amid the political upheaval following the 2014 overthrow of President Blaise Compaoré (Broadhead, 2015).

I provide two figures that are consistent with the hypothesis. Figure 1.1 Panel A depicts the residual plot where I regress FGM rates of adult women on regime durability, controlling for year fixed effects, using country-year observations in multiple waves of DHS and MICS surveys. There is statistically significant negative correlation, showing that a country-year with 10 years of regime durability is associated with a 4.5-percentagepoint smaller FGM rate. Panel B shows time variation. It depicts the FGM prevalence of the Akan ethnic group, which is divided between Ghana and Ivory Coast. Both subgroups started with similar FGM rates and the same regime durability; however, starting in 1966, Ghana experienced a period of political unrest, while Ivory Coast remained under stable authoritarian leadership. The difference in the FGM rates jumps following shocks to regime durability, and FGM is more prevalent among Akan people in Ghana than among Akan people living in Ivory Coast. This case study shows how ethnic groups arbitrarily divided by state borders and having the same cultural norms can change over time due to changes in regime durability. 
Figure 1.1: Regime durability and FGM: Cross-sectional and time variation

Panel A:

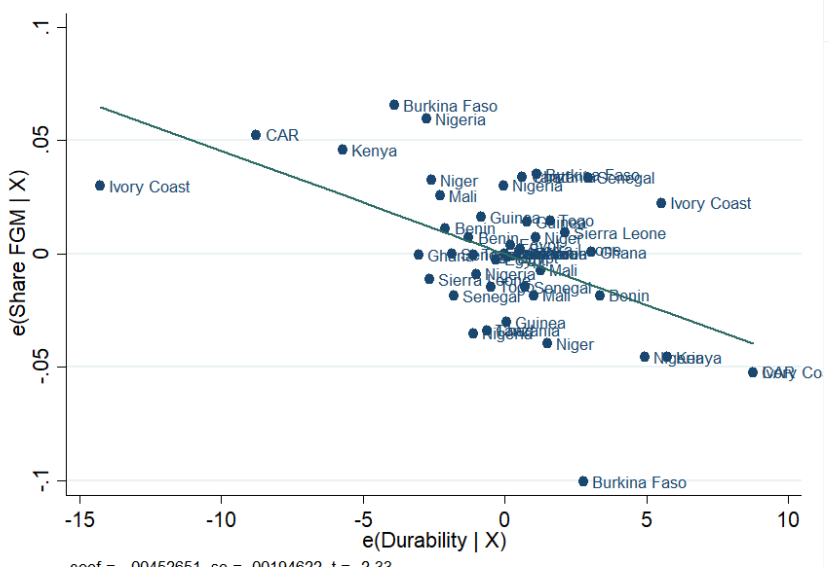

Panel B:

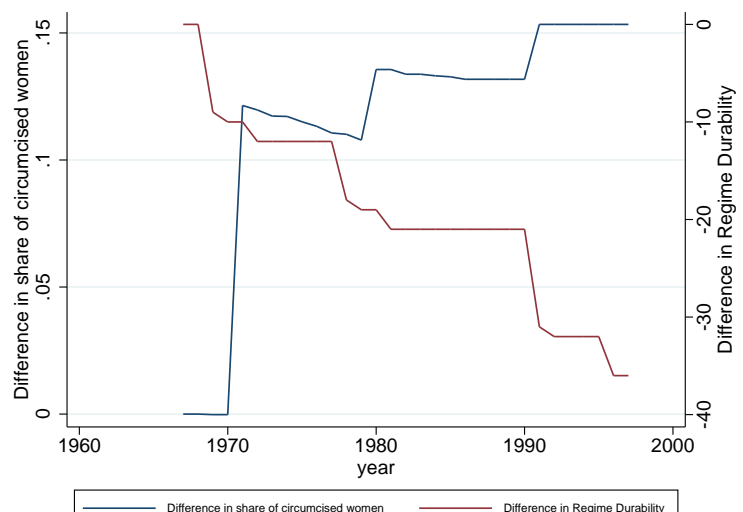

Notes: Panel A reports a residual plot of the survey-level (55 observations-surveys for 23 countries) regression of FGM rates on regime durability with year fixed effects. The dependent variable is a total share of circumcised women. The explanatory variable is regime durability. Panel B shows differences in FGM rates and regime durability for the Akan ethnic group. The Akan ethnic group is partitioned between Ghana and Ivory Coast. On the left Y-axis, I plot the share of women who were circumcised in a country and ethnicity during year $t$. On the right Y-axis, I plot differences in regime durability between Ghana and Ivory Coast.

To conclude, FGM is a cultural norm and an important mechanism of the marriage market. Fostering expectations that anti-FGM policy will last long enough to ensure a successful marriage-market outcome in the future without doing FGM now helps to solve the coordination problem. And, evidence exists that the stability of regimes promoting antiFGM programs affects the persistence of FGM - countries with more durable regimes exhibit lower rates of FGM.

\section{Data}

FGM The data on FGM come from the Demographic and Health Survey (DHS) and Multiple Indicator Cluster Survey (MICS). ${ }^{7}$ Of the more than 70 available surveys that contained "female genital cutting" questions, I use 55 surveys (see Table C.1) that contain

\footnotetext{
${ }^{7}$ DHS and MICS data are comparable since they have similar variables and similar methods of data collection.
} 
a question about the age of circumcision, since the age is crucial for me to construct the share of circumcised women in a given country-ethnicity and year. ${ }^{8}$ Survey data contain the following information on adult women (above 18 years old): whether a woman is circumcised or uncircumcised, age, age of circumcision, marital status, age of marriage, years of education, ethnicity and religion (of the respondents in the DHS dataset and of the household heads in the MICS dataset), country and region, and area of residency (rural/urban status). Figure D.2 depicts the geographical distribution of the shares of circumcised women averaged over all surveys used in this paper. Summary statistics of these samples appear in Table C.2.

Using variables for year of birth and age of circumcision, I construct a retrospective person-year panel, keeping only those years of women's lives during which they are eligible for circumcision. Specifically, each unit (woman) starts with $t$ observations, where $t$ is the age at the time of the survey. Then I drop all observations for the years when the woman is already circumcised, as circumcision is an "absorbing state" and can be done only once. I also drop all the years of a woman's life when her age is above the maximum or below the minimum age of circumcision for her ethnolinguistic group. For example, if a woman $i$ who belongs to ethnic group $e$ with eligible age for circumcision being 5 to 9 years, and she is circumcised at age 7 , she will have three observations (age $\in\{5,6,7\}$ ). And if woman $j$ from the same ethnic group is uncircumcised, she will have 5 observations (age $\in\{5,6,7,8,9\}$ ). The age at which the girl is circumcised can vary significantly depending on ethnic and regional cultural traditions and on religious denomina-

\footnotetext{
${ }^{8}$ Overall, my sample spans 23 countries: Benin, Burkina Faso, Central African Republic, Cameroon, Chad, Ivory Coast, Egypt, Gambia, Ghana, Guinea, Iraq, Kenya, Mali, Mauritania, Niger, Nigeria, Senegal, Sierra Leone, Somalia, Tanzania, Togo, and Yemen. Before 1990, Yemen counts as two countries: North Yemen and South Yemen.
} 
tion (Yoder, Abderrahim and Zhuzhuni, 2004; UNICEF, 2013). ${ }^{9}$ I discuss alternative ways of defining eligible age for circumcision in Appendix A.

The main dependent variable is the percentage of women who were circumcised in a country and ethnicity during year $t$. It is calculated as follows:

$$
f g m_{c e t}=\frac{\sum_{i=1}^{N_{c e t}} \mathbb{I}\left(f g m_{i c e t}=1\right)}{N_{c e t}} \times 100
$$

where $N_{c e t}$ is the total number of women eligible for circumcision in year $t$, country $c$, and ethnicity $e, \mathbb{I}\left(f g m_{\text {icet }}=1\right)$ is a dummy which equals to one if woman $i$ in country $c$ and ethnicity $e$ is circumcised in year $t$.

Regime Durability The main explanatory variable is political regime durability. As the primary measure of regime durability, I use the DURABLE variable proposed by Polity IV (Marshall and Cole, 2013), which calculates the number of (cumulative) years since the last substantive change in authority characteristics, defined as a three-point change in the Polity2 score. Thus, if the change in authority characteristics is smaller than three, durability of a political regime goes up by one every year. When a substantial change happens, the durability measure goes to zero in the year of change.

Polity score ranges from +10 (strongly democratic) to -10 (strongly autocratic). Here, an example for democracy would be Ghana after 2005. It has a Polity score of 8 since it hosts competitive elections, has near parity for executive authority executive constraints,

\footnotetext{
${ }^{9}$ To clarify this, in Figure D.3 I provide a cumulative distribution of the age at which FGM is performed using examples of two ethnicities: For the first (Akan), the eligible age for FGM is 5 to 18 years; for the second (Guerze), the eligible age is 1 to 30 years. For most ethnicities, the age of eligibility ranges from 0 to 18 years. I also plot the hazard and survival functions for my sample of circumcised females and present the density of age of FGM, and a cumulative distribution of the age when FGM was performed (Figure D.4).
} 
and has limited political liberalization with institutionalized and open electoral competition. On the other end of the spectrum (with a score of -9) would be authoritarian regime of Mobutu Sese Seko in the Democratic Republic of Congo (then, Republic of Zaire).

Regime durability has nothing to do with autocracy or democracy; a durable autocracy and a durable democracy will both have a similar effect on FGM. For example, Julius Nyerere, the president of Tanzania from 1964 to 1985, started the country's first anti-FGM campaign in 1968, and by the time of the latest survey, Tanzania's FGM rate was less than $10 \%$ among women 15 to 49 . Throughout Nyerere's rule, Tanzania had a Polity 2 score of -6 , but this highly durable regime nearly eradicated FGM.

Changes in score can evince a spectrum of autocratic and democratic characteristics. For example, gaining a "competitive" level of "competitiveness of political participation" or "unlimited authority" in "constraints on chief executive" at year $t$ would count as a three-point change in Polity score and would set durability to zero. However, gaining a "transitional" of "competitiveness of political participation" or "slight to moderate limitations" in "constraints on chief executive" would have no effect on regime durability on that year. Thus durability does not change with a change of authoritarian or democratic leader, only when significant constitutional changes happen.

Thus, the measure Durabilityct assumes that the regime stability is a martingale, and the best predictor of future regime stability is current regime durability. This is consistent with scholars' views on the durability of a political regime (e.g., Clemens and Cook, 1999; Gates et al., 2006). ${ }^{10}$

\footnotetext{
${ }^{10}$ Scholars agree that the best predictor of future regime durability is current regime durability (Gasiorowski, 1995), and it is often used in the economic (Girma and Shortland, 2008) and political science (Li, 2005; Piazza, 2007, 2008) literature. Because a Polity2 score does not distinguish the quality of
} 
Since regime durability is available only after countries of sub-Saharan Africa gained independence, the final dataset spans from 1970 to $2013 .{ }^{11}$

Anti-FGM Policies I measure presence of an anti-FGM policy as a dummy equal to one if country $c$ at year $t$ has any criminal legislation against FGM. The data come from the 28 too many country-specific briefs entitled "The Law and FGM." I augment these data with information from Harvard's list of "Laws of the World on FGM" and Rahman and Toubia (2000).

Further details and description of control variables appear in Appendix A.

\section{Empirical Specification, Identification, and Results}

\subsection{Empirical Specification, Identification, and Research Design}

In my main analysis, I investigate how regime durability affects the share of newly circumcised women. My identification is based on the fact that FGM is a cultural tradition that exists at the ethnic-group level. When ethnic groups were randomly partitioned between different countries, two identical (in terms of cultural norms) groups of people were now living across national borders subject to different shocks of regime stability, conditional on observables. Thus the research design is a difference-in-differences analysis. ${ }^{12}$ By using country-ethnicity fixed effects and year fixed effects, I identify a differential

national leaders, I offer alternative ways to measure regime durability in Section 4, where I use other possible measures of regime durability to show that my results are robust and that I do indeed capture the effect of regime stability.

${ }^{11}$ All results are robust to the exclusion of the first five years and/or last five years for each country.

${ }^{12}$ In contrast with Michalopoulos and Papaioannou (2014), who use the same identification strategy to study the effect of national institutions on economic outcomes, I cannot use historical ethnic maps to identify ethnic homelands, due to the nature of the dependent variable. Most of the surveys containing an FGM questionnaire have no GPS coordinates, only the ethnicity and the subnational region name. However, I use rich individual survey data that contain information about the ethnic group of the respondents as well 
time trend across country-ethnicity in regime stability conditional on observed national institutions and economic factors.

For example, assume that $N$ ethnic groups are divided between two countries, A and $\mathrm{B}$, and that there are two time periods, $t$ and $t+1$. In country $\mathrm{A}$ and year $t$, the regime has lasted for $m_{1}$ years, so the durability is equal to $m_{1}$. The regime does not experience a three-point change in its Polity 2 score in year $t+1$, and its durability is $m_{1}+1$. In country $B$ and year $t$, its durability is $m_{2}$. However, country $B$ experiences a substantial change in its political regime in $t+1$ that is larger than three points. Thus, its durability in $t+1$ is equal to zero. I label the first country Stable and the second one Unstable. Thus we can derive the difference-in-differences estimator:

$$
\hat{\beta}_{D D}=\left(\overline{f g m}_{\text {Stable }, t+1}-\overline{f g m}_{\text {Stable }, t}\right)-\left(\overline{f g m}_{\text {Unstable }, t+1}-\overline{f g m}_{\text {Unstable }, t}\right),
$$

where $\overline{f g m}$ is the mean FGM prevalence of $N$ ethnic groups.

With multiple ethnicities and time periods, I employ the general framework considered in Bertrand, Duflo and Mullainathan (2004) and Hansen (2007). The baseline empirical specification is as follows:

$$
\operatorname{fgm}_{\text {cet }}=\alpha+\beta \text { Durabilityct }+\Pi X_{c e t}+\Psi \Gamma_{c t}+\mu_{c e}+\lambda_{t}+\epsilon_{c e t},
$$

where $f g m_{c e t}$ is the number of women who are circumcised divided by the number of women eligible for FGM of ethnicity $e$ in country $c$ and year $t$. The variable Durabilityct is the regime durability of country $c$ in year $t$. Matrix $X_{c e t}$ represents the set of individualas data about FGM prevalence. In addition, I explore time variation in formal institutions, and regime durability in particular. 
level variables averaged by ethnicity and country (including age, education, opinion about FGM, shares of major religions, polygamous households, rural population, and size of marriage market), and matrix $\Gamma_{c t}$ contains the set of country-year-specific variables (such as GDP per capita, population, number of active NGO sites, foreign aid, fertility, population growth, a dummy for anti-FGM legislature, and institutional controls). By using country-ethnicity fixed effects $\mu_{c e}$, I account for unobserved heterogeneity that varies at the ethnic and national levels such as geographic conditions. Time fixed effects $\lambda_{t}$ absorb general trends in the world's efforts to eliminate FGM and global economy shocks that may affect regime durability. Because the main variable of interest varies at the country-year level, I cluster standard errors at the country level to be conservative.

The parameter of interest is $\beta$, and $\beta<0$ indicates that durable political regimes have lower rates of FGM. The first threat to identifying $\beta$ as a causal impact is reverse causality. Individual's decision on FGM should not affect regime durability; however, a coordinated decision of an ethnic group or several ethnic groups can. First, when people want to abolish FGM by voting for a candidate that will in the future support its abolishment, it won't generate a shock of regime durability in the contemporaneous period. In addition, in some specifications, I will include country-ethnicity linear trends to absorb the increase of the regime durability by one unit due to the fact that regime survived another year. The surviving variation in regime durability is only from big negative shocks in regime durability that can only come from a significant change in a country's institution, due to, e.g., revolution. Using 6th wave of Afrobarometer (for the subsample of countries that appear in my sample, i.e., where FGM exists) only $1 \%$ of the respondents mentioned "Gender issues/women's rights" as one of the three most important problems of their 
country. Hence, it is very unlikely that peoples' concerns regarding FGM will be strong enough to mobilize the people to start a revolution which overturns the regime. ${ }^{13}$

Second, there could be omitted variables that correlate with both regime stability and FGM rates, biasing the estimates. For example, income or inequality might be correlated with regime stability, because richer countries are more stable, while higher inequality might lead to political unrest. Both variables can also affect households' decisions on FGM by changing the value of opportunities on the marriage market. Thus, I add the log of GDP per capita as a control variable that serves as a summary measure of economic development at the country level, while I account for inequality through country-ethnicity fixed effects. ${ }^{14}$ I also construct measures of income at the country-ethnicity-year level among women who are eligible for circumcision, including the share of households that own various assets, such as a car, television, or radio. ${ }^{15}$ I control for the countries' total population and population growth rates in case more populous countries have more volatile political regimes. I control for infant mortality and average life expectancy to capture the effects of governmental health programs that may correlate with anti-FGM movements. Finally, I control for demographic characteristics that potentially determine FGM rates and may correlate with regime durability, such as share of major religious de-

\footnotetext{
${ }^{13}$ Rather than contemporaneous reverse causality, what is more likely to bias results is the lagged share of circumcised girls. While FGM practices in a given year and ethnicity will unlikely affect the durability of the country's political regime in the same year, lagged FGM share might affect current regime durability through economic underdevelopment. To address this concern in Column I of Table B.3, I include a lagged dependent variable in the dynamic panel specification.

${ }^{14}$ In case regime durability correlates with inequality that was also linked to FGM (Ross et al., 2016), I would need to control for the Gini coefficient. However, the World Bank's data on Gini is limited for years before 2000. Nevertheless, my results hold if I use available Gini data with a dummy for missing years, or if I use proxies for poverty.

${ }^{15}$ Radio ownership also reflects people's media access (e.g., to absorb government information campaigns).
} 
nominations, size of the marriage market, share of polygamist families, public opinion about FGM, a proxy for women's education, and share of rural area population.

One may be concerned that it is actually some other institutional characteristics are driving the results. For example, state capacity to enforce anti-FGM laws can be highly correlated with regime durability while impacting the eradication of FGM. I address this concern by proxying for state capacity using severity of terrorist attacks based on the Global Terrorism Database (GTD, 2015) while directly controlling for a dummy for antiFGM legislation. In case that democratic and autocratic countries are different in their attitudes toward and approach to eradicating FGM, I add an indicator of the democratic regime based on the composite democracy score from Polity IV (Persson and Tabellini, 2005). ${ }^{16}$

NGOs and foreign aid may play an important role in fighting against FGM in Africa. In addition, durable regimes may receive more foreign aid or be more likely to host NGOs. To address this concern, I control for the number of NGOs and the total amount of foreign aid that each country receives each year.

Finally, migration is not likely to bias my results. FGM is predicted by current domicile and not by the birthplaces of women or their parents, since the local marriage market is what dictates the type and necessity of FGM (Gallo and Abdisamed, 1985 and Diabate and Mesplé-Somps, 2019). ${ }^{17}$ In case migration correlates with the size of the marriage market, I control for it and other demographic factors, such as age, fertility, and prevalence of polygamy.

\footnotetext{
${ }^{16}$ In my sample, regime durability correlates only with a proxy for democracy and international war (I control for them in all specifications) and does not correlate with other institutional controls (see Table C.3).

${ }^{17}$ Nevertheless, all results hold if I drop all women who were born abroad.
} 


\subsection{Results}

Table 1 reports the main results on the impact of regime durability on FGM rates. Panel A Column I estimates Equation 3.1 with only country-ethnicity and year fixed effects. The point-estimate of interest $\hat{\beta}$ is negative and statistically significant at the $10 \%$ level. It indicates that a one-standard-deviation larger change in regime durability leads to a 0.1-standard-deviation larger decrease in the share of newly-circumcised women. To interpret the result, let's think about a country that experiences a large shock in authority characteristics after 11 years with a stable regime, compared to another country that remains politically stable. After the shock, the country's regime durability goes from 11 to 0 while the other goes up by 1 ; this leads to a 5.5 -percentage-point larger increase in its FGM rate than the other country.

Columns II-IX sequentially add controls for demographic, political economy, and socioeconomic variables. As discussed above, democracy and state capacity might correlate with regime stability and enforcement of anti-FGM legislation. Socioeconomic and demographic controls might correlate with marriage-market conditions and political regime stability. The extent of foreign aid and the number of NGOs may also correlate with regime stability and intensity of anti-FGM activities. Including the aforementioned controls does not affect the size or significance of my coefficient of interest. ${ }^{18}$

Panel B re-estimates Equation 3.1 employing ethnicity fixed effects and country fixed effects instead of country-ethnicity effects; the results are similar to those in the previous panel. In case that marriage markets are defined at a smaller geographic level than

\footnotetext{
${ }^{18}$ As I have only 23 countries/clusters, following Cameron, Gelbach and Miller (2008), I employ wild bootstrapping of the standard errors: the coefficient for specification in Column IX is still significant with the $\mathrm{p}$-value $=0.022$.
} 


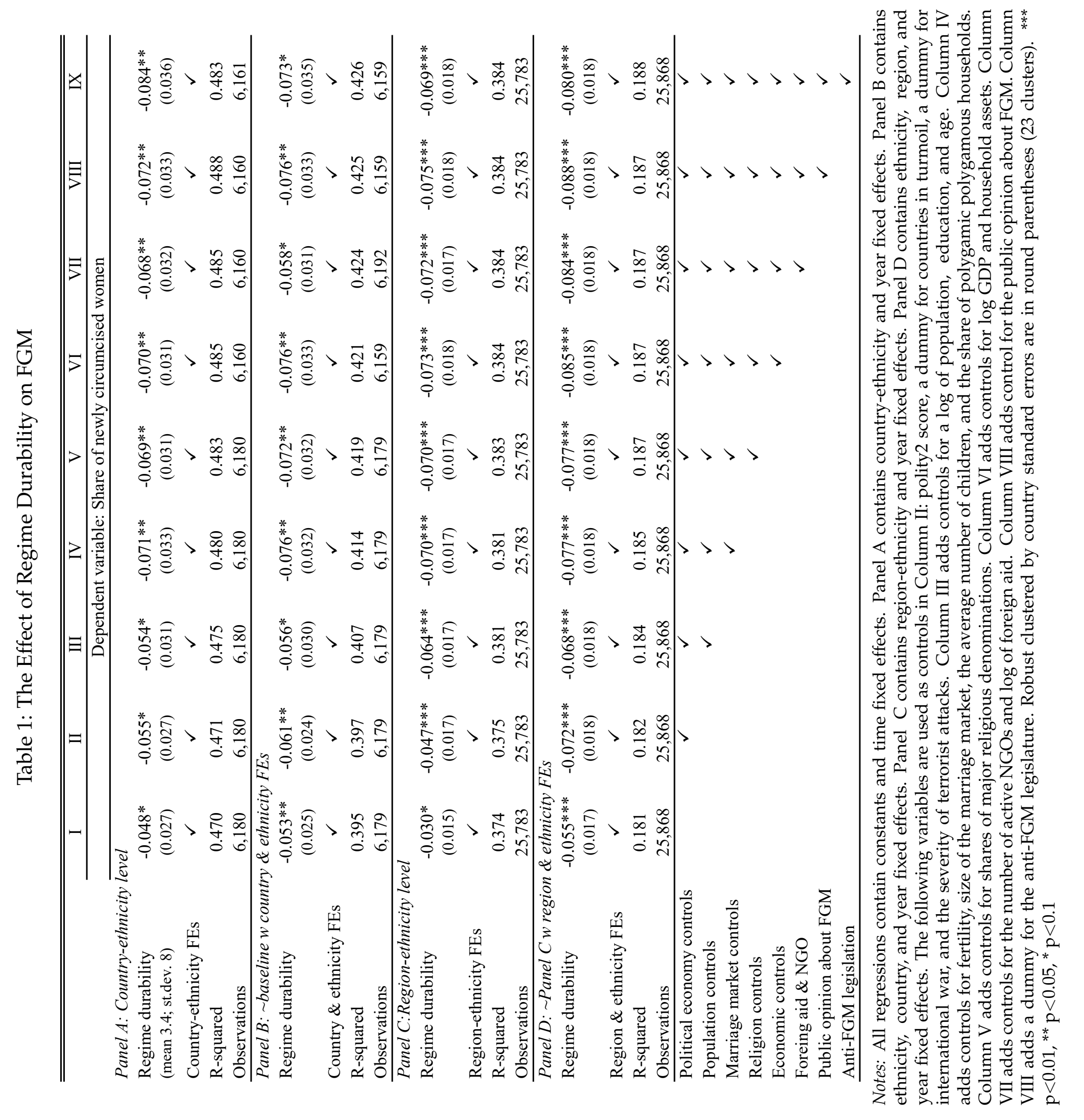


country-ethnicity, I use region-ethnicity-year panels with region-ethnicity fixed effects in Panel C. ${ }^{19}$ Panel D replicates Panel C with ethnicity fixed effects and region fixed effects. Even with the demanding specifications in these two panels, the results are similar.

I provide additional robustness checks for the main results in Appendix D.5. First, I show that the effect of regime stability does not depend on the functional form (Table B.1). Results hold if I use the square root or inverse hyperbolic sin of regime durability. I also don't find evidence of the quadratic term being significant. Results also hold when I define durability using a set of categorical variables (5-to-10, 11-to-15, 16-to-20, and $>20$ ), keeping 0-to-4 as a baseline. I find that 5-10 years is enough for people to start to believe that a regime will continue to fight against FGM, and that regimes lasting longer than 10 years have the same effect.

Second, I show that results are not driven by specific regions. Using subsample analysis, I find that FGM rates in urban and rural areas does not respond differentially to the regime durability (Table B.2). In addition, the results are not driven by the Middle East and North Africa regions. Finally, in my identification strategy, ethnic groups that are unique to certain countries provide no identifying variation and only reduce standard errors. Results hold if I limit the sample to ethnic groups that live in more than one country (Column IV of Table B.2).

Third, in the case of serial correlation of the dependent variable, it may be important to control the lagged dependent variable on the right-hand side of Equation 3.1. My results are robust to the inclusion of a lagged dependent variable in the dynamic panel

\footnotetext{
${ }^{19}$ Mackie and LeJeune (2009) and UNICEF (2013) point out that marriage markets in African countries are very narrow; they can be limited by ethnic group but also by smaller regional tribal identity. For a map depicting how administrative regions cross ethnic boundaries, see Figure D.5.
} 
specification (Blundell and Bond, 1998) in Column I of Table B.3.

Finally, using an individual-level panel of surveyed women, I find similar effects of regime durability on the probability of circumcision using a Cox Proportional Hazard model and conditional logit (Columns II-III of Table 2, see Section B.4 for details).

\subsection{Evidence from the Individual-Level Data of Daughters}

In this section, I use individual-level panel data for daughters of surveyed women to account for mother-specific factors that may affect the understanding of costs and benefits of FGM and perceptions of regime stability. Specifically, mothers play an important role in the decision to circumcise the girls, and comparing daughters of the same mother can take into account the mother's time-invariant characteristics. I construct the panel using surveys on women whose daughters' circumcision situation is recorded retrospectively. As before, I keep only the years when the daughter is eligible for circumcision and drop the years when she is already circumcised. I estimate the following specification

$$
D\left(\operatorname{fgm}_{i(m) c t}=1\right)=\gamma+\phi \text { Durability }_{c t}+\Pi X_{i t}+\Psi \Gamma_{c t}+\mu_{m}+\lambda_{t}+\epsilon_{i(m) c t},
$$

where observation $i(m) c t$ is a daughter $i$ of mother $m$ at year $t$ in country $c$, and $D\left(f g m_{i(m) c t}=\right.$ 1 ) is a dummy variable if the daughter was circumcised in year $t . X_{i t}$ includes the daughter's age and order of birth, and $\mu_{m}$ is the mother fixed effect. As in Equation 3.1, $\Gamma_{c t}$ is a matrix of country-year controls and $\lambda_{t}$ is year fixed effects. Country-ethnicity fixed effects are absorbed by mother fixed effects.

The parameter of interest $\phi$ captures how regime stability affects the probability of a daughter being circumcised by using the variation in regime durability within the 
mother's life, conditional on her generic attitude toward FGM. Again, the coefficient estimate on regime durability is negative and statistically significant (Column I of Table 2): a one-standard-deviation larger increase in regime durability leads to a 1.7-percentagepoint larger decrease in the probability of being circumcised.

Table 2: The Effect of Regime Durability on FGM: Individual-Level Data

\begin{tabular}{lccc}
\hline & I & II & II \\
\hline Dependent variable: & $\begin{array}{c}\text { Dummy if daughter } \\
\text { is circumcised }\end{array}$ & \multicolumn{2}{c}{$\begin{array}{c}\text { Dummy if woman } \\
\text { is circumcised }\end{array}$} \\
\hline \hline & LPM & Cox P-H-M & Conditional logit \\
\hline Durability & $-0.0014^{*}$ & $-0.0032^{*}$ & $0.873^{* * *}$ \\
& $(0.0005)$ & $(0.0016)$ & $(0.026)$ \\
Individual-level controls & $\checkmark$ & $\checkmark$ & $\times$ \\
Fixed effects & Mother & $\checkmark$ & Individual \\
Sample & Daughter line number & All & All switchers \\
Aggregation level & Individual & Individual & Individual \\
Observations & 39,068 & $3,388,649$ & $1,709,261$ \\
R-squared & 0.624 & & 0.946 \\
\hline \hline
\end{tabular}

Notes: All regressions contain constants. Column I is estimated using OLS with mother fixed effects. Column II is estimated using the Cox Proportional Hazard model and contains marginal effects. Column III is estimated using conditional logit and contains odds ratios. I use the same set of controls as in the baseline specification in Table 1, Panel A, Column IX. In addition, cubic spline is used as a control in Column II. Robust clustered by country standard errors are in parentheses for Column I. Robust clustered by sample standard errors are in parentheses for Columns II and III. ${ }^{* * *} \mathrm{p}<0.01,{ }^{* *} \mathrm{p}<0.05,{ }^{*} \mathrm{p}<0.1$

\subsection{Channels: Anti-FGM Legislation and Support for FGM}

In this section, I show the channel though which regime durability affects persistence and decay of the cultural norm of FGM. It is reasonable to expect that only when countries have anti-FGM policies in place in a certain year, would a durable regime encourage people to abandon FGM. I build on the preferred specification in Column IX, Panel A of Table 1 by adding country-ethnicity-specific time-trends, in Column I of Table 3. Although the specification is extremely demanding, the regime durability coefficient remains negative 
and significant. This specification should account for possible country-ethnicity-specific trends in efficiency of anti-FGM policy and countries' regime durability. ${ }^{20} \mathrm{I}$ also report the coefficient for an indicator variable equal to one if country $c$ at year $t$ has anti-FGM legislation. ${ }^{21}$ The coefficient is positive and non-significant. Column II adds the interaction of regime durability and a dummy for anti-FGM policy. The estimate for durability becomes zero, and the interaction absorbs all the effect. A one-standard-deviation larger increase in regime durability conditional on anti-FGM policy leads to a 0.1-standard-deviation larger decrease in the share of circumcised women.

Table 3: Regime Durability and Anti-FGM Legislation

\begin{tabular}{|c|c|c|c|c|}
\hline \multirow[b]{3}{*}{ Sample } & $\overline{\mathrm{I}}$ & 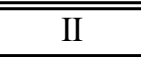 & IIII & IV \\
\hline & \multicolumn{4}{|c|}{ Dependent variable: Share of newly circumcised women } \\
\hline & \multicolumn{2}{|c|}{ Baseline } & $\begin{array}{c}\text { Women who } \\
\text { support FGM }\end{array}$ & $\begin{array}{l}\text { Women who } \\
\text { oppose FGM }\end{array}$ \\
\hline Durability & $\begin{array}{l}-0.041^{*} \\
(0.023)\end{array}$ & $\begin{array}{l}-0.015 \\
(0.018)\end{array}$ & $\begin{array}{c}-0.03 \\
(0.030)\end{array}$ & $\begin{array}{l}-0.09^{*} \\
(0.047)\end{array}$ \\
\hline Durability $\mathrm{x}$ anti-FGM policy & & $\begin{array}{c}-0.053^{* *} \\
(0.022)\end{array}$ & & \\
\hline Anti-FGM policy & $\begin{array}{c}0.626 \\
(0.499)\end{array}$ & $\begin{array}{l}1.219^{*} \\
(0.636)\end{array}$ & $\checkmark$ & $\checkmark$ \\
\hline Durability x support for FGM & & & & \\
\hline Country-ethnicity linear trends & $\checkmark$ & $\checkmark$ & & \\
\hline R-squared & 0.595 & 0.596 & 0.403 & 0.449 \\
\hline Observations & 6,161 & 6,161 & 6,161 & 6,161 \\
\hline
\end{tabular}

Notes: This table uses the most conservative specification in Table 1, Panel A, Column IX. Column I adds country-ethnicity-specific linear trends. Column II adds interaction of the dummy for anti-FGM policy and regime durability. Columns III and IV estimate the baseline specification on panels constructed using subsamples of women who support and oppose FGM. Robust standard errors clustered by country are in parentheses. ${ }^{* * *} \mathrm{p}<0.01,{ }^{* *} \mathrm{p}<0.05,{ }^{*} \mathrm{p}<0.1$

\footnotetext{
${ }^{20}$ Specification with country-ethnicity fixed effects also helps to address possible reverse causality problem when population that wants to abolish FGM votes for the existing government pushing for the eradication of FGM.

${ }^{21}$ Table C.1 contains years when anti-FGM laws were enacted in each country. I use the earliest year of anti-FGM legislation for each country; however, results are robust if I use the dates of subsequent anti-FGM laws. The coefficient for anti-FGM policy is hard to interpret causally because countries that have high levels of FGM may be more likely to adopt these laws.
} 
The results are robust to using more-detailed definitions of anti-FGM policies (in Table B.7). A country can have multiple laws against FGM or one law that includes several articles against FGM. I construct several dummy variables to summarize the characteristics of the laws/articles: (1) with clear definition of FGM; (2) criminalizing performance of FGM; (3) criminalizing arrangement, assistance, or procurement of FGM; (4) criminalizing failure to report incidents of FGM; (5) punishment for the participation of medics in acts of FGM; and (6) punishment for practice of cross-border FGM. I also construct the total number of anti-FGM laws/articles, the first-principal component of these six dummies, and the presence of a national anti-FGM strategy. I find significant effects of the total number, first-principal component of individual laws/article dummies, national strategy, and dummies for (1) and (2). The rest of the dummies have no significant effects.

In addition to national policies, women's intrinsic willingness to abolish the practice also matters. In places where people actually support FGM, durability should not matter. One question in the questionnaire asks explicitly whether a woman thinks FGM should continue with $0-1$ answers. ${ }^{22}$ Then I construct the ethnicity-country-year panel separately for women who support FGM and the ones who oppose it. In Columns III and IV, I estimate the baseline specification on these panels constructed using subsamples of women. In the panel using women who oppose FGM, the coefficient estimate of regime durability is statistically significant and larger in magnitude than in the baseline regression (Column IV). Among women who support the tradition of FGM, the estimate is smaller and non-significant (Column III). This could be because they have some disutility from abol-

\footnotetext{
${ }^{22}$ Here, following UNICEF (2013), I assume that if a woman supports FGM, her mother also used to support FGM.
} 
ishing this tradition; yet, they also do not want their circumcised daughters to end up in a marriage market that does not favor circumcision, in case other people in the community decide to abolish it.

\section{Alternative Explanations and Robustness Checks}

Up to this point, I have found strong evidence that ethnic groups residing in countries with durable political regimes abolish FGM faster than the same ethnic groups in countries with less durable regimes. Nevertheless, there might exist other potential alternative explanations of my main results. In this section, I consider such alternative explanations and provide a set of robustness and sensitivity checks.

Validity and Robustness of the Main Regime Durability Measure First, in the main result, the regime durability presented by Polity IV shows the number of (cumulative) years since the last substantive change in authority characteristics (defined as a three-point change in the Polity score). A substantial change can also be defined on different measures of the autocracy-to-democracy spectrum (Barron, Miguel and Satyanath, 2014). In particular, I construct alternative measures of regime durability using three-point changes in (i) the Przeworsky Democracy Index (PDI) (Cheibub, Gandhi and Vreeland, 2010); (ii) the Freedom House Polity Index (FHPI) (Freedom House, 2013); (iii) data by Geddes, Wright and Frantz (2014) (GWF); or (iv) first-principal component of the durability based on the main measure and the three alternative measures. The coefficient estimates of the baseline specification 3.1 are shown in Columns II-V of Table B.4; they are similar in terms of signs and magnitudes to those of the baseline regression, which I repeat in Column I 
for comparison.

Second, I present some suggestive evidence on how my measure of regime durability is associated with people's expectations about how the (persistence of the) current government will affect local life. I use data from the 6th Afrobarometer wave, which has a question on whether respondents expect that government will solve their "local problems in the near future (within five years)," and I define a dummy which equals to one if they do believe so. I construct a country-year panel dataset that contains the share of people who think that government will solve local problems within the next five years. I estimate the following OLS specification:

$$
\text { Solve local problems in } 5 \text { years }_{c t}=\alpha+\delta \text { Durability }_{c t}+\Gamma \mathbb{X}_{c t}+\lambda_{t}+\eta_{c t},
$$

where Solve local problems in 5 years ${ }_{c t}$ is the share of respondents in country $c$ in year $t$ who think that government will solve local problems within the next five years; matrix $\mathbb{X}_{c t}$ is a set of institutional controls for Polity score and executive constraints, and $\lambda_{t}$ represents time fixed effects.

I find that durability correlates with respondents' expectations that government will solve their local problems in the near future, which is consistent with my hypothesis about durability capturing people's expectations on how likely a government will continue to push its anti-FGM policy (Column I of Table B.8). ${ }^{23}$

Finally, a change in national leadership without changes in my durability measure may induce changes in the government's attitude toward FGM. I first use the Archigos 4.0 database (Goemans, Gleditsch and Chiozza, 2009) to define all changes in national

\footnotetext{
${ }^{23}$ I have only a few observations, so I don't add many controls in the regression. However, my results hold if I add a different set of institutional or economic controls.
} 
leaders (both, democratic and autocratic), and construct a dummy for whether a new leader comes into power in country $c$ at year $t$. I add that indicator variable to the baseline specification to show that the effect of regime durability is not driven purely by changes in nations' leaders (Column II of Table B.5). While the new leader's dummy is somewhat negative and significant, it does not affect the coefficient of regime durability.

I also consider a situation when I directly control for the type of political regime, type of regime transition, or authoritarian regime changes without changes in polity score (e.g., if a personality authoritarian regime transitions to the party regime). For it, I use the " $\mathrm{Au}$ tocratic Regimes" dataset by Geddes, Wright and Frantz (2014) where the authors codify all autocratic regimes and construct a measure on the change of any autocratic leader or political regimes. I start by re-estimating the baseline specification and controlling for the dummy of the political regime switch (Column III), and my coefficient estimate for regime durability remains the same. The coefficients also stay stable when: (1) dropping years when there was a regime change but not a Polity score change (Column IV); and (2) controlling for the type of regime transition, a dummy for violence after the regime change, and type of authoritarian regime (party/personality) in Columns V-VII. ${ }^{24}$

Confounding Country-Level Institutional and Economic Conditions In my main analysis, I control for the set of most important institutional controls, such as Polity2 score, dummy for international war, and dummy for regimes in-turmoil. In this section, I show the robustness of the main result by controlling for additional institutional measures.

\footnotetext{
${ }^{24}$ Transition to democracy or autocracy is only one particular type of shock to regime durability, and many other shocks take the form of autocratic/democratic regimes becoming more or less autocratic/democratic. The study of particular regimes and how ethnic composition of the regimes affect FGM is a very interesting topic which goes beyond the scope of the current paper and deserves to be studies separately in future research.
} 
They are: (i) constraint on executive (Column II of Table B.9); (ii) a binary democracy indicator from Acemoglu et al. (2014) (Column III); (iii) revolutions, government crises, number of anti-governmental demonstrations, and dummy for civil wars (Columns IV, V, VI, and VII); (iv) all six of these variables (Column VIII); and (v) additional institutional controls (for political assassinations, riots, strikes, purges, guerrilla warfare, and the weighted conflict measure from Banks and Wilson (2016) in Column IX. ${ }^{25}$

Table B.10 also shows that my results are not driven by international trade-related outcomes. Controlling on import, export, trade-to-GDP ratio, and average weighted tariffs does not explain my results.

Health Outcomes, Education, and Empowerment of Women Certain health programs, NGO activities, and modernization of the society can be associated with regime durability and also affect FGM. To address this concern, in Table B.6, I test whether durability affects different types of health outcomes. First, infant mortality, HIV, and life expectancy are likely to be affected by health programs and NGO activities. I show in Columns I-III that regime durability has no significant impact on them. In Column VI, I also show that durability is not associated with provision of medical goods and services. This suggests that durability works only through opposition to traditional practices and not through health reforms. Second, fertility is associated with both NGO activities (such as condom distribution) and modernization. I also find no effect of durability on the fertility rate (Column IV). Finally, modernization can have impacts on education. Again, there is no

\footnotetext{
${ }^{25}$ I also explore the sensitivity of my results to potential omitted variables, following approaches proposed in Oster (2017). I show that the scope for omitted-variable bias is limited, and the influence of unobservable factors should be at least 2.6 times larger relative to observable factors to explain the relationship between regime stability and FGM prevalence (Table B.11).
} 
statistically significant effect of regime durability on education outcomes (Column V). I also find no effect of regime durability on the government's effort to empower women (Column VII).

Ethnic and Religious Identity People may choose to associate more with their ethnic identity when the regime is not stable, and in turn ethnic identity can strengthen their attachment to the cultural norms, including FGM. ${ }^{26}$ To test this hypothesis, I use data from the the 4th, 5th, and 6th Afrobarometer waves, which contain information regarding people's ethnic and national identity and employ the same specification as in equation $4.1 .^{27}$ I show that durability is not correlated with ethnic identity, suggesting that durability is unlikely to affect FGM through reawakening ethnic traditions (Column I of Table B.12). In Column II, I also show that durability is also not associated with religiosity.

Nonclassical Measurement Error in the FGM rates Another alternative explanation is related to the possible nonclassical measurement error in the dependent variable. If women are afraid of being prosecuted by stable regime that is trying to eradicate FGM, they may underreport their FGM status. ${ }^{28}$ In this case, I will capture the effect of underreporting rather than the effect of regime durability.

\footnotetext{
${ }^{26}$ For example, if an adverse shock to durability increases peoples ethnic identity relative to their national identity, they may be more likely to follow their cultural traditions of FGM and thus my coefficient will be upward-biased. Indeed, Ananyev and Poyker (2018) show that civil conflict in Mali adversely affected people's national identity. I have already shown that the results are robust to inclusion of proxies for conflict; here, I show that regime durability does not correlate with ethnic identity.

${ }^{27} \mathrm{DHS}$ and MICS do not have ethnic identity questions.

${ }^{28}$ Gibson et al. (2018) show that only highly educated respondents are more inclined to hide their high support for FGM and provide more socially desirable answers. In addition, Jackson et al. (2003) find that women in Ghana tend to misreport whether their daughters are circumcised but not whether they themselves were circumcised. As most respondents would have undergone FGM in childhood (Panel B of Figure D.4) as a result of their parents' choices, Jackson et al. (2003), UNICEF (2013), and Kudo (2018) believe that women usually truthfully report their FGM status.
} 
First, in cases where only educated women misreport their FGM status (Gibson et al., 2018), using individual-level data I directly control for education and socioeconomic status of respondents (see Appendix B.4). Second, in cases where the misreporting is womanspecific, the specification with mother fixed effects in Table 2 should address the issue. Third, I provide suggestive evidence using Afrobarometer's 6th wave where I choose the countries where respondents are more likely to reveal to the interviewer something as "dangerous" as their FGM status. The idea is that if people are not afraid of openly saying that they are ready to violate the law, they should also be truthful in reporting their FGM status. Using the question "People must obey the law," I range all countries in my sample from the least law-abiding (Nigeria, 59 percent) to the most (Senegal, 87 percent). Then I re-estimate the baseline specification on the subsample of the least obedient half of the countries. The resulting coefficient -0.126 (s.e. 0.051) is larger in magnitude than the baseline but is not statistically different from it. Thus, I conclude that if people in this subsample are honest enough to say that they don't need to obey the law then they should also be honest in their responses regarding FGM.

\section{Regime Durability and Other Cultural Norms: Evidence from Child Marriage and Polygamy}

Regime durability may affect other harmful cultural norms where their persistence is affected by people's expectation on the government's continued efforts to eradicate them. While there are many harmful traditional practices (see Giuliano and Nunn, 2017), the 
data on them are limited. The only two such practices for which the data exist and are spread across enough countries for me to have variation in regime durability are child marriage and polygamy.

Child marriage is commonly defined as a formal marriage or informal union before age 18. There is a growing literature on the harmful consequences of child marriage - it affects girls' physical and mental health, education, and labor-force participation (Singh and Samara, 1996 and Raj et al., 2009). Child marriage is also a cultural norm where families have to comply with the group's norm of the marriage age in order to get better outcomes in the marriage market. African countries are trying to eradicate the practice and enforce anti-child-marriage legislation (Wang, 2016). It is similar to FGM since the decision to commit to child marriage needs to happen early and if a girl remains unmarried by age 18, she risks finding no husband if everyone else sticks to the childmarriage tradition. Thus, expectations about the continued efforts by the government to eliminate the practice crucially affect parents' decisions.

On the other hand, although polygamy may also be harmful to various aspects of women's life, the expectation does not play an important role, especially since governments are not actively seeking to abolish the practice. Thus, I expect that more durable regimes move faster in abolishing child marriage; however, I expect regime durability to have no effect on the traditional practice of polygamy. ${ }^{29}$

I construct the share of newly married girls below the age of 18 the same way as for my main dependent variable (FGM). For robustness, I also use alternative thresholds

\footnotetext{
${ }^{29}$ It is also important to check the effect of regime durability on polygamy because polygamy is an important factor in the persistence of FGM (Becker, 2018). Thus, regime durability might have an indirect effect on FGM through polygamy.
} 
for child marriage (14, 15, 16, and 17 years). To measure polygamy, I use the share of polygamous households. The results appear in Table 4. Columns I-V show results for child marriage. Countries with durable regimes abolish child marriage faster: a onestandard-deviation larger change in regime durability leads to a 0.06-standard-deviation larger decrease in the share of newly-wed young girls (Column I). I also collected detailed data on anti-child-marriage laws to show that the effect is stronger in countries where child marriage laws are more strict (Column VI). ${ }^{30}$ Column VII indicates no significant effect of regime durability on polygamy. These results confirm my hypothesis that ethnic groups living under stable political regimes abolish cultural norms faster if those norms are being targeted by the government and they rely on people's expectations.

Table 4: Effect of Regime Durability on Child Marriage and Polygamy

\begin{tabular}{|c|c|c|c|c|c|c|c|}
\hline & I & $\overline{\mathrm{II}}$ & $\overline{\mathrm{IIII}}$ & IV & $\mathrm{V}$ & VI & VII \\
\hline & \multicolumn{7}{|c|}{ Dependent variable: } \\
\hline & \multicolumn{6}{|c|}{ Share of newly married women below } & Share of \\
\hline & 14 years old & 15 years old & 16 years old & 17 years old & 18 years old & 18 years old & households \\
\hline Durability & $\begin{array}{l}-0.03 * * \\
(0.014)\end{array}$ & $\begin{array}{l}-0.04 * * \\
(0.014)\end{array}$ & $\begin{array}{c}-0.05 * * * \\
(0.014)\end{array}$ & $\begin{array}{c}-0.05 * * * \\
(0.016)\end{array}$ & $\begin{array}{c}-0.05 * * \\
(0.020)\end{array}$ & $\begin{array}{c}0.04 \\
(0.045)\end{array}$ & $\begin{array}{l}-0.007 \\
(0.006)\end{array}$ \\
\hline $\begin{array}{l}\text { Durability } x \\
\text { anti-child-marriage laws }\end{array}$ & & & & & & $\begin{array}{l}-0.06^{* *} \\
(0.028)\end{array}$ & \\
\hline Legislation & $\checkmark$ & $\checkmark$ & $\checkmark$ & $\checkmark$ & $\checkmark$ & $\checkmark$ & $\checkmark$ \\
\hline R-squared & 0.175 & 0.251 & 0.337 & 0.376 & 0.394 & 0.395 & 0.860 \\
\hline Observations & 5,672 & 5,742 & 5,784 & 5,815 & 5,836 & 5,836 & 6,208 \\
\hline
\end{tabular}

Notes: This table uses the most conservative specification in Table 1, Panel A, Column IX, but employes alternative outcome variables. Robust standard errors clustered by country are in parentheses ( 23 clusters). ${ }^{* * *} \mathrm{p}<0.01,{ }^{* *} \mathrm{p}<0.05,{ }^{*} \mathrm{p}<0.1$

\footnotetext{
${ }^{30}$ Anti-child-marriage laws are coded in Svanemyr et al. (2013). I defined as zero if a country does not have a child marriage law or allows girls under 14 to be married. I assigned the value of one for countries that have minimum wage laws but allow child marriage with parental consent or customary laws. Countries, where girls can't be married under 18, were assigned the value of two.
} 


\section{Conclusion}

In this paper, I show how the eradication of harmful cultural traditions and norms is affected by a particular institutional factor, political regime stability. I take advantage of the fact that the borders of contemporary African states were arbitrarily drawn by colonial administrations in Europe, partitioning numerous ethnic groups into different countries. The partitioned ethnic groups have identical cultures but reside in territories subject to different country-level institutions, thus I can identify the causal effect of regime stability on the persistence of FGM practices. I find that a one-standard-deviation larger change in regime durability leads to a 0.1-standard-deviation larger decrease in the share of newly-circumcised women. I also find similar effects of regime durability on the other cultural norm targeted by government eradication campaigns and subject to expectations on future marriage markets — child marriage.

I find that only when countries have anti-FGM policies in place, would a durable regime encourage people to abandon FGM. My results are not explained by the presence of NGOs or foreign aid, are not confounded by other institutional factors, and are not a by-product of health policies or policies aiming to educate or empower women. Nor are my results explained by perception of ethnic or religious identity during regimedurability shocks. Overall, I conclude that durable political regimes are helpful in abandoning harmful practices that rely on delayed realization of costs and benefits since people expect the regime to last long enough to successfully change the cultural norm.

Outdated social norms and culture can impede economic development and harm the well-being of the community members, especially vulnerable groups such as children and 
women. The eradication of such norms and practices relies heavily on the coordinated move among all community members, making the task extremely challenging. In this paper, I show that the stability of formal institutions can help substantially in solving the coordination issue by strengthening people's faith in coordinated efforts. Thus, factors that hamper regime durability could have long-run social and economic impacts, even reversing the previously-achieved progress. My results suggest that in terms of eradication efforts, the returns in durable regimes are much higher than in unstable ones, and the efforts need to be persistent enough to move society forward.

\section{References}

Acemoglu, Daron, Suresh Naidu, Pascual Restrepo, and James A Robinson. 2014. "Democracy does cause growth." National Bureau of Economic Research.

Alesina, Alberto, and Paola Giuliano. 2015. "Culture and Institutions." Journal of Economic Literature, 53(4): 898-944.

Alesina, Alberto, William Easterly, and Janina Matuszeski. 2011. "Artificial states." Journal of the European Economic Association, 9(2): 246-277.

Ananyev, Maxim, and Michael Poyker. 2018. "State Capacity and Demand for Identity: Theory and Evidence from Political Instability in Mali."

Banks, Arthur S, and Kenneth A Wilson. 2016. "Cross-National Time-Series Data Archive. Databanks International."

Barron, Manuel, Edward Miguel, and Shanker Satyanath. 2014. "Economic Shocks and Democratization in Africa." Political Science Research and Methods, 2(01): 33-47.

Beachey, Raymond Wendell. 1976. The slave trade of eastern Africa. Vol. 1, Barnes \& Noble.

Becker, Anke. 2018. “On the Economic Origins of Constraints on Women's Sexuality."

Bertrand, Marianne, Esther Duflo, and Sendhil Mullainathan. 2004. "How Much Should We Trust Differences-in-Differences Estimates?" Quarterly journal of economics, 119(1): 249-275.

Bicchieri, Cristina, and Annalisa Marini. 2015. "Female Genital Mutilation: Fundamentals, Social Expectations and Change." 
Bisin, Alberto, and Thierry Verdier. 2000. "“Beyond The Melting Pot": Cultural Transmission, Marriage, And The Evolution Of Ethnic And Religious Traits." Quarterly Journal of Economics, 955-988.

Bisin, Alberto, and Thierry Verdier. 2001. "The economics of cultural transmission and the dynamics of preferences." Journal of Economic theory, 97(2): 298-319.

Bisin, Alberto, Eleonora Patacchini, Thierry Verdier, and Yves Zenou. 2011. "Formation and persistence of oppositional identities." European Economic Review, 55(8): 1046-1071.

Bisin, Alberto, Giorgio Topa, and Thierry Verdier. 2009. "Cultural transmission, socialization and the population dynamics of multiple-trait distributions." international Journal of Economic theory, 5(1): 139-154.

Bjalkander, Owolabi, Laurel Bangura, Bailah Leigh, Vanja Berggren, Staffan Bergstrom, and Lars Almroth. 2012. "Health complications of female genital mutilation in Sierra Leone." International Journal of Women's Health, 4(1): 321-331.

Blundell, Richard, and Stephen Bond. 1998. "Initial conditions and moment restrictions in dynamic panel data models." Journal of econometrics, 87(1): 115-143.

Boddy, Janice. 1982. "Womb as oasis: the symbolic context of pharaonic circumcision in rural Northern Sudan." American Ethnologist, 9(4): 682-698.

Brady, Margaret. 1999. "Female genital mutilation: complications and risk of HIV transmission." AIDS patient care and STDs, 13(12): 709-716.

Broadhead, Ivan. 2015. “Activists Fear Rise of FGM Cases in Burkina Faso." Voanews.

Caldwell, John C, Israel Olatunji Orubuloye, and Pat Caldwell. 2000. “Female Genital Mutilation: Conditions of decline." Population Research and Policy Review, 19(3): 233-254.

Cameron, A Colin, Jonah B Gelbach, and Douglas L Miller. 2008. "Bootstrap-based improvements for inference with clustered errors." The Review of Economics and Statistics, 90(3): 414-427.

Cheibub, José Antonio, Jennifer Gandhi, and James Raymond Vreeland. 2010. “Democracy and dictatorship revisited." Public Choice, 143(1-2): 67-101.

Clemens, Elisabeth S, and James M Cook. 1999. "Politics and institutionalism: Explaining durability and change." Annual review of sociology, 441-466.

Diabate, Idrissa, and Sandrine Mesplé-Somps. 2019. "Female genital mutilation and migration in Mali: do return migrants transfer social norms?" Journal of Population Economics, 32(4): 1125-1170. 
Diop, Nafissatou Jocelyne, Modou Mbacke Faye, Amadou Moreau, Jacqueline Cabral, Hélène Benga, Fatou Cissé, Babacar Mané, Inge Baumgarten, and Molly Melching. 2004. The TOSTAN program: evaluation of a community based education program in Senegal. Population Council Washington.

Easton, Peter, Karen Monkman, and Rebecca Miles. 2003. "Social policy from the bottom up: abandoning FGC in sub-Saharan Africa." Development in Practice, 13(5): 445-458.

Efferson, Charles, Sonja Vogt, Amy Elhadi, Hilal El Fadil Ahmed, and Ernst Fehr. 2015. "Female genital cutting is not a social coordination norm." Science, 349(6255): 14461447.

Ellickson, Robert C. 1989. "A hypothesis of wealth-maximizing norms: Evidence from the whaling industry." Journal of Law, Economics, E Organization, 83-97.

Ellickson, Robert C. 1991. Order without law. Harvard University Press.

Elnashar, Aboubakr, and R Abdelhady. 2007. "The impact of female genital cutting on health of newly married women." International Journal of Gynecology \& Obstetrics, 97(3): 238-244.

Fan, Xinyu, and Lingwei Wu. 2018. "The Economic Motives of Foot-binding."

Fenske, James. 2015. "African polygamy: Past and present." Journal of Development Economics, 117: 58-73.

Freedom House. 2013. "Freedom in the World 2013." Democratic breakthroughs in the balance.

Gallo, Pia Grassivaro, and Marian Abdisamed. 1985. "Female circumcision in Somalia: Anthropological traits." Anthropologischer Anzeiger, 311-326.

García-Jimeno, Camilo. 2016. "The political economy of moral conflict: An empirical study of learning and law enforcement under prohibition." Econometrica, 84(2): 511570 .

Gasiorowski, Mark J. 1995. "Economic crisis and political regime change: An event history analysis." American Political Science Review, 89(04): 882-897.

Gates, Scott, Håvard Hegre, Mark P Jones, and Håvard Strand. 2006. "Institutional inconsistency and political instability: Polity duration, 1800-2000." American Journal of Political Science, 50(4): 893-908.

Geddes, Barbara, Joseph Wright, and Erica Frantz. 2014. "Autocratic breakdown and regime transitions: A new data set." Perspectives on Politics, 12(02): 313-331. 
Gibson, Mhairi A, Eshetu Gurmu, Beatriz Cobo, María M Rueda, and Isabel M Scott. 2018. "Indirect questioning method reveals hidden support for female genital cutting in South Central Ethiopia." PloS one, 13(5): e0193985.

Gigerenzer, Gerd. 2007. Gut feelings: The intelligence of the unconscious. Penguin.

Girma, Sourafel, and Anja Shortland. 2008. "The political economy of financial development." Oxford Economic Papers, 60(4): 567-596.

Giuliano, Paola, and Nathan Nunn. 2017. "Understanding cultural persistence and change." National Bureau of Economic Research.

Goemans, Henk E, Kristian Skrede Gleditsch, and Giacomo Chiozza. 2009. "Introducing Archigos: A dataset of political leaders." Journal of Peace research, 46(2): 269-283.

GTD. 2015. National Consortium for the Study of Terrorism and Responses to Terrorism (START). Global Terrorism Database [Data file]. Retrieved from www.start.umd.edu/gtd.

Hakin, Ly. 2001. "Impact of female genital mutilation on maternal and neonatal outcomes during parturition." East African Medical Journal, 78(5): 255-258.

Hansen, Christian B. 2007. "Generalized Least Squares inference in panel and multilevel models with serial correlation and fixed effects." Journal of Econometrics, 140(2): 670-694.

Hartung, John. 1976. "On Natural Selection and the Inheritance of Wealth." Current Anthropology, 17(4): 607-622.

Hayford, Sarah R. 2005. "Conformity and change: community effects on female genital cutting in Kenya." Journal of Health and Social Behavior, 46(2): 121-140.

Howard, Janet A, and Mhairi A Gibson. 2017. "Frequency-dependent female genital cutting behaviour confers evolutionary fitness benefits." Nature ecology $\mathcal{E}$ evolution, 1(3): 0049.

Jackson, Elizabeth F, Patricia Akweongo, Evelyn Sakeah, Abraham Hodgson, Rofina Asuru, and James F Phillips. 2003. "Inconsistent reporting of female genital cutting status in northern Ghana: Explanatory factors and analytical consequences." Studies in Family Planning, 34(3): 200-210.

Jones, Heidi, Nafissatou Diop, Ian Askew, and Inoussa Kaboré. 1999. "Female genital cutting practices in Burkina Faso and Mali and their negative health outcomes." Studies in family planning, 30(3): 219-230.

Kahneman, Daniel. 2011. Thinking, fast and slow. Macmillan.

Koso-Thomas, Olayinka. 1987. "The circumcision of women: a strategy for eradication." 
Kudo, Yuya. 2018. "Female Genital Cutting and Long-term Adjustment of Marriage Markets: Evidence from West Africa."

Leimbach, Dulcie. 2014. "With Mali in Political Turmoil, High FGM Rates Persist."

Lightfoot-Klein, Hanny. 1989. Prisoners of ritual: An odyssey into female genital circumcision in Africa. Haworth Press, Inc.

Li, Quan. 2005. "Does democracy promote or reduce transnational terrorist incidents?" Journal of Conflict resolution, 49(2): 278-297.

Mackie, Gerry. 1996. "Ending footbinding and infibulation: A convention account." American Sociological Review, 999-1017.

Mackie, Gerry. 2003. "Female Genital Cutting: a harmless practice?" Medical anthropology quarterly, 17(2): 135-158.

Mackie, Gerry, and John LeJeune. 2009. "Social dynamics of abandonment of harmful practices: a new look at the theory." Special series on social norms and harmful practices, 2009-06.

Makhlouf Obermeyer, Carla. 2005. "The consequences of female circumcision for health and sexuality: an update on the evidence." Culture, Health $\mathcal{E}$ Sexuality, 7(5): 443-461.

Marcus, Rachel, and Ella Page. 2014. "Changing discriminatory norms affecting adolescent girls through communication activities."

Marshall, Monty G., and Benjamin R. Cole. 2013. "Polity IV data set and codebook. Available at www.systemicpeace.org/polity/polity4.htm (accessed 21 March 2015)."

Michalopoulos, Stelios, Alireza Naghavi, and Giovanni Prarolo. 2018. "Trade and Geography in the Spread of Islam." The Economic Journal, 128(616): 3210-3241.

Michalopoulos, Stelios, and Elias Papaioannou. 2014. "National Institutions and Subnational Development in Africa." The Quarterly Journal of Economics, 129(1): 151-213.

Michalopoulos, Stelios, and Elias Papaioannou. 2018. "Spatial patterns of development: A meso approach." Annual Review of Economics, 10: 383-410.

Michalopoulos, Stelios, Louis Putterman, and David N Weil. 2019. "The influence of ancestral lifeways on individual economic outcomes in Sub-Saharan Africa." Journal of the European Economic Association, 17(4): 1186-1231.

Morison, Linda, Caroline Scherf, Gloria Ekpo, Katie Paine, Beryl West, Rosalind Coleman, and Gijs Walraven. 2001. "The long-term reproductive health consequences of female genital cutting in rural Gambia: a community-based survey." Tropical Medicine E International Health, 6(8): 643-653. 
North, Douglass C. 1990. Institutions, institutional change and economic performance. Cambridge university press.

Orchid Project. 2013. "Country: Guinea-Bissau."

Oster, Emily. 2017. "Unobservable selection and coefficient stability: Theory and evidence." Journal of Business E Economic Statistics, 1-18.

Persson, Torsten, and Guido Enrico Tabellini. 2005. The economic effects of constitutions. MIT press.

Piazza, James A. 2007. "Draining the swamp: Democracy promotion, state failure, and terrorism in 19 Middle Eastern countries." Studies in Conflict E Terrorism, 30(6): 521-539.

Piazza, James A. 2008. "Do democracy and free markets protect us from terrorism?" International Politics, 45(1): 72-91.

Rahman, Anika, and Nahid Toubia. 2000. Female Genital Mutilation: A practical guide to worldwide laws $\mathcal{E}$ policies. Zed Books.

Raj, Anita, Niranjan Saggurti, Donta Balaiah, and Jay G Silverman. 2009. "Prevalence of child marriage and its effect on fertility and fertility-control outcomes of young women in India: a cross-sectional, observational study." The Lancet, 373(9678): 1883-1889.

Ross, Cody T, Pontus Strimling, Karen Paige Ericksen, Patrik Lindenfors, and Monique Borgerhoff Mulder. 2016. "The Origins and maintenance of female genital modification across Africa." Human Nature, 27(2): 173-200.

Schelling, Thomas C. 1980. The strategy of conflict. Harvard university press.

Shell-Duncan, Bettina. 2001. "The medicalization of female "circumcision": harm reduction or promotion of a dangerous practice?" Social Science E Medicine, 52(7): 1013-1028.

Shell-Duncan, Bettina. 2008. "From health to human rights: Female genital cutting and the politics of intervention." American Anthropologist, 110(2): 225-236.

Shell-Duncan, Bettina, and Yiva Herniund. 2007. "Are There "Stages of Change" in the practice of Female Genital Cutting? Qualitative Research Finding from Senegal and the Gambia." African journal of reproductive health, 10(2): 57-71.

Shell-Duncan, Bettina, Katherine Wander, Ylva Hernlund, and Amadou Moreau. 2011. "Dynamics of change in the practice of female genital cutting in Senegambia: testing predictions of social convention theory." Social Science E Medicine, 73(8): 1275-1283.

Singh, Susheela, and Renee Samara. 1996. "Early marriage among women in developing countries." International family planning perspectives, 148-175. 
Svanemyr, Joar, Elisa Scolaro, V Chandra-Mouli, K Blondeel, and M Temmerman. 2013. "The contribution of laws to change the practice of child marriage in Africa." InterParliamentarian Union, Geneva.

Tabellini, Guido. 2008. “The Scope of Cooperation: Values and Incentives." The Quarterly Journal of Economics, 123(3): 905-950.

TOSTAN. 2013. "Annual Reports and Financials."

Toubia, Nahid. 1994. "Female circumcision as a public health issue." New England Journal of Medicine, 331(11): 712-716.

UK Department for International Development. 2013. “Towards Ending Female Genital Mutilation/Cutting in Africa and Beyond."

UNFPA, and UNICEF. 2013. "Joint Evaluation of the UNFPA-UNICEF Joint Programme on Female Genital Mutilation/Cutting (FGM/C): Accelerating Change." UN Population Fund (UNFPA)-UN Children's Fund, (UNICEF).

UNICEF. 2007. "Coordinated strategy to abandon female genital mutilation/cutting in one generation." Report, New York, NY: UNICEF. www. unicef. org/evaldatabase/files/fgmc tostan eng SENEGAL. pdf.

UNICEF. 2008. "Long-term Evaluation of the Tostan Programme in Senegal: Kolda, Thiès, Fatick Regions." Statistics and Monitoring Section, New York: UNICEF.

UNICEF. 2013. "Female Genital Mutilation/Cutting: a statistical overview and exploration of the dynamics of change." UNICEF.

Vogt, Sonja, Nadia Ahmed Mohmmed Zaid, Hilal El Fadil Ahmed, Ernst Fehr, and Charles Efferson. 2016. "Changing cultural attitudes towards female genital cutting." Nature.

Wagner, Natascha. 2015. "Female Genital Cutting and Long-Term Health ConsequencesNationally Representative Estimates across 13 Countries." The Journal of Development Studies, 51(3): 226-246.

Wang, Vibeke. 2016. "Ending child marriages-new laws bring progress but hurdles remain." CMI Insight.

Weber, Karin. 2012. "Public Declarations on Female Genital Mutilation. Cutting Abandonment." United Nations Uganda.

WHO. 1998. "Female genital mutilation: an overview." In Female genital mutilation: an overview. World Health Organization.

Yoder, P. Stanley, Noureddine Abderrahim, and Arlinda Zhuzhuni. 2004. "Female genital cutting in the Demographic and Health Surveys: a critical and comparative analysis."

Young, H Peyton. 2015. "The evolution of social norms." Annual Review of Economics, 7(1): 359-387. 


\section{Online Appendix}

to

“Regime Stability

and the Persistence of Traditional Practices" 
Online Appendix - Not for Publication

\section{A Data Appendix}

In this subsection, I explain how the control variables used in this study were constructed.

Robustness of the alternative definition of the eligible age for circumcision Based on the age-of-circumcision for each country $c$ and ethnicity $e$, I calculate "eligible age for circumcision" (eligible ce $_{\text {) }}$ by taking the range of years between the minimum and maximum ages of circumcision for each ethnicity and country. For the sake of computational simplicity, I drop all observations for women whose circumcision age is above 25 years (which is $0.06 \%$ of the sample). The resulting eligible years are similar to those listed for some ethnic groups in UNICEF (2013). My results hold if I arbitrarily make the eligible age between 0 and 18; however, I chose to follow anthropological literature and set up an ethnicity-specific eligible age. If anti-FGM legislation narrows the window for circumcision age (e.g., Camilotti (2015) documents it in Senegal), in stable regimes I will have a wider window for the circumcision. However it would work against me finding a negative effect of regime durability. All results are robust for calculating the eligible age of circumcision when taking religion $(d)$ into account (eligible $_{c e d} \in$ $\left[\min \left(\right.\right.$ fgm age $\left._{i c e d}\right), \max \left(\right.$ fgm age $\left.\left.\left._{i c e d}\right)\right]\right)$ or by using region $(r)$ instead of country $(c)$ $\left(\right.$ eligible $_{r(c) e} \in\left[\min \left(\right.\right.$ fgm age $\left._{i r(c) e}\right), \max \left(\right.$ fgm age $\left.\left.\left._{i r(c) e}\right)\right]\right)$.

Classical measurement error in the dependent variable The data used in the study are clearly imperfect; despite the high response rate, respondents' answers might be unin- 
Online Appendix - Not for Publication

tentionally incorrect. $^{31}$ Approximately 7.8 percent of women didn't indicate their FGM status or exact age of circumcision. In this case, I might have a measurement error in the dependent variable. However, assuming classical measurement error, this will only increase the variance without influencing the consistency of interest coefficients. To back this assumption, I create a dummy variable Missing $_{i}$ (equal to 1 if data is missing, and equal to 0 if not) and regress it on the treatment variable. Regime durability has no significant effect on Missing $_{i}$, and I eliminated those observations from the dataset. The fact that I dropped some of the observations of women who have undergone FGM and don't remember their circumcision age will bias my results against finding evidence of the effect of regime stability on FGM prevalence. Also if ethnic groups that are less likely to stop FGM reduce the eligible age of FGM and are more pronounced in the DHS/MICS samples it can cause underestimation of the results. However, inclusion of country-ethnicity fixed effects and country-ethnicity time trends remedies this potential problem. I explore the issue of nonclassical measurement error in greater detail in Section 4.

Construction of other variables There are about 221 ethnicities in the dataset. As ethnicity data for some samples (Egypt, Mauritania, and Tanzania) do not exist because they have not been recorded and for some (Niger and Nigeria) partially missing, I constructed ethnicity by using language and/or religion. For example, almost all Muslims in Nigeria (more than $90 \%$ in the Nigerian sample from 1999) belong to the Hausa/Fulani group; for all missing observations, I assigned all Muslims in the Nigerian samples (2003 and

\footnotetext{
${ }^{31}$ For example, in Figure D.4 we can see by the ages given by the respondents that there are distinct peaks at 20,25,30,35, and 40; these can be explained by the fact that the women do not remember their exact ages.
} 
Online Appendix - Not for Publication 2008) as Hausa/Fulani. All Christians speaking the Coptic language or Orthodox Christians not speaking the Amharic language in Egypt are considered Copts. Respondents speaking Zarma in Niger were assigned to the Djerma/Songhai ethnicity. I dropped ethnicities for which no FGM cases were reported (mostly foreigners). Finally, I united all ethnicities having fewer than 10 individuals into "Other "Name of the Country"" groups; this resulted in a total of 139 ethnicities.

Because some samples contained highly detailed names for religious denominations while some had very broad names for religious affiliations, in order to control for religion I created dummies for Islam, Catholic, Protestant, Orthodox, Other Christian, Indigenous Beliefs, Atheists, and Other. For example, I merged the respondents belonging to smaller religious groups, which were described as Traditional/spiritual/animist, traditional, animist, voodoo, etc., into a single Indigenous Beliefs category.

To account for the capacities of marriage-market, I construct a Size of the marriage mar$k e t$, which describes the fraction of all women who were married during year $t$ divided by the number $N_{i e r t}^{u m}$ of women that might be married (if they are more than 10 years old and not yet married) in region $r$, year $t .{ }^{32}$

$$
\text { Size of the marriage market } \operatorname{cet}_{\text {cet }}=1-\frac{\sum_{i=1}^{N_{\text {iert }}^{u m}} \mathbb{I}\left(\text { married }_{\text {icet }}=1\right)}{N_{\text {icet }}^{u m}} \text {. }
$$

For the individual-level data specification, I produced the Marriage Switch variable,

\footnotetext{
${ }^{32}$ The territory that determines the size of the marriage market can be a region, a city, a village, or a cluster of villages. However, since I can construct reliable aggregated data only on country-ethnicity level, I assume that it is also on a country-ethnicity level. It will cause a measurement error, but I assume that even if it is unlikely to correlate with FGM it should not correlate to regime durability.
} 
Online Appendix - Not for Publication which is equal to 0 unless a woman is married, is equal to 1 once she marries, and remains equal to unity for all years after. This variable is crucial, as FGM is closely related to the marriage market, and the fact that a woman is already married and remains uncircumcised should significantly decrease her chances of being circumcised in the future.

$$
\text { Marriage } \text { Switch }_{i t}= \begin{cases}1 & \text { if } \text { married }_{i}=1 \text { and } t \geq s, \\ 0 & \text { if } \text { married }_{i}=1 \text { and } t<s, \\ 0 & \text { if } \text { married }_{i}=0,\end{cases}
$$

where married $_{i}=0$ if woman $i$ was never married and equal to unity if she was, and $s$ is the "Age of the first Marriage."

Lastly, I use the Total Years of Schooling and Age variables to construct the variable of schooling for each woman for each year of her life $t$ in which she is eligible for circumcision:

$$
\text { Years of } \quad \text { Schooling }_{i t}= \begin{cases}0 & t \in[0 ; 6], \\ \sum_{s=1}^{t} 1-6 & t \in\left[7 ; T Y S_{i}\right] \\ T Y S_{i} & t>T Y S_{i r} .\end{cases}
$$

While computing Years of schooling $i^{\prime}$ I assume that all women begin their education at the age of 7 and study continuously year by year without breaks. ${ }^{33}$

Below I list the control variables I use in the paper, by source:

\footnotetext{
${ }^{33} \mathrm{All}$ results also hold if I assume that women start to begin their education at the age of 6 or 8 .
} 
Online Appendix - Not for Publication

- DHS and MICS: FGM-related variables, demographic variables, ethnicity, religion, polygamy data, household assets, geographical data, children line numbers;

- WDI (World Bank Group, 2016): fertility, life expectancy, infant mortality, HIV prevalence;

- PennTables 8.1 (Feenstra, Inklaar and Timmer, 2015): GDP per capita (PPP), population, population growth;

- Cross-National Time-Series Data Archive (Banks and Wilson, 2016): assassinations, general strikes, guerrilla warfare, government crises, purges, riots, revolutions, antigovernment demonstrations, weighted conflict index;

- Polity IV (Marshall and Cole, 2013): regime durability, polity2, executive constraints (xconst). In addition, I create an indicator for democratic countries based on the POLITY $2_{c t} \in[-10 ; 10]$ score by : Democracy $y_{c t}=P O L I T Y 2_{c t} / 10 \quad$ if $P O L I T Y 2_{c t} \geq$ 0 and 0 otherwise. The variable Democracyct $\in[0 ; 1]$ represents an authoritarian political regime if Democracyct $=0$ and a full democracy if Democracyct $=1$.

- Rahman and Toubia (2000) and UNICEF (2013): anti-FGM legislation;

- Archigos 4.0 database (Goemans, Gleditsch and Chiozza, 2009): data about leaders deaths, including their age, gender, type of entry and exit, causes of death;

- Correlates of War War Data, 1816 - 2007 (v4.0) (Sarkees and Wayman, 2010): international and civil wars; 
Online Appendix - Not for Publication

- NGO AidMap, by InterAction (www.ngoai dmap.org/): NGO locations, budgets;

- OECD, the World Bank, the Asian Development Bank, and the Inter-American Development Bank: AidFlow (www.aidflows.org/about/): international aid inflow;

- Global Terrorist Database (GTD, 2015): number of deaths, number of accidents, location and year of accidents;

- Cheibub, Gandhi and Vreeland (2010): Przeworsky Democracy Index;

- Freedom House (Freedom House, 2013): Freedom House Polity Index;

- Geddes, Wright and Frantz (2014): list of autocratic regimes. 
Online Appendix - Not for Publication

\section{B Additional Results}

\section{B.1 Alternative Functional Form of Durability}

Table B.1: Effect of Regime Durability on FGM: Testing for Alternative Functional Form and Nonlinearity

\begin{tabular}{|c|c|c|c|c|c|}
\hline & I & II & III & IV & V \\
\hline & \multicolumn{5}{|c|}{ Dependent variable: Share of newly circumcised women } \\
\hline Durability & $\begin{array}{c}-0.08 * * \\
(0.036)\end{array}$ & & & $\begin{array}{l}-0.07 * * \\
(0.031)\end{array}$ & \\
\hline Log (durability) & & $\begin{array}{l}-0.39 * * \\
(0.181)\end{array}$ & & & \\
\hline Sqrt (durability) & & & $\begin{array}{c}-0.49 * * \\
(0.227)\end{array}$ & & \\
\hline Durability $^{2}$ & & & & $\begin{array}{c}-0.00 \\
(0.001)\end{array}$ & \\
\hline Durability (5-10 years) & & & & & $\begin{array}{l}-0.52 * \\
(0.291)\end{array}$ \\
\hline Durability ( $11-15$ years) & & & & & $\begin{array}{c}-1.47 * * * \\
(0.513)\end{array}$ \\
\hline Durability (16-20 years) & & & & & $\begin{array}{c}-1.26^{* *} \\
(0.591)\end{array}$ \\
\hline Durability ( $>20$ years) & & & & & $\begin{array}{l}-1.47^{*} \\
(0.790)\end{array}$ \\
\hline R-squared & 0.495 & 0.495 & 0.494 & 0.495 & 0.495 \\
\hline Observations & 6,161 & 6,161 & 6,161 & 6,161 & 6,161 \\
\hline
\end{tabular}

Notes: This table uses the most conservative specification in Table 1, Panel A, Column IX, but uses alternative functional forms of regime durability. Robust clustered by country standard errors are in parentheses (23 clusters). ${ }^{* * *} \mathrm{p}<0.01,{ }^{* *} \mathrm{p}<0.05,{ }^{*} \mathrm{p}<0.1$

In Table B.1, I test the robustness of my results to the functional form of my explanatory variable and nonlinearity of the effect of regime durability on FGM. In Column I, I present baseline results from Column IX of Panel A of Table 1. Results hold if I use log or square root of durability (Columns II and III). ${ }^{34}$ In Column IV, I test whether the effect of

\footnotetext{
${ }^{34}$ In fact, instead of $\log$, I use inverse hyperbolic sine transformation $\left(\log \left(y_{i}+\left(y_{i}^{2}+1\right)^{1 / 2}\right)\right)$. It is approximately equal to $\log \left(2 y_{i}\right)$ or $\log (2)+\log \left(y_{i}\right)$, so it can be interpreted in exactly the same way as a standard logarithmic variable but without doing $\log \left(1+y_{i}\right)$ (Burbidge, Magee and Robb, 1988).
} 
B.1 Alternative Functional Form of Durability Online Appendix - Not for Publication regime durability is nonlinear by including the square of the explanatory variable; however, durability squared is non-significant. In Column V, I try to use a more flexible nonlinear specification that also seeks to shed light on what level of durability is sufficient for people to believe that the government will continue to push for the eradication of FGM. I create several indicator variables for regimes that last 5-to-10, 11-to-15, 16-to-20, and more than 20 years (with a baseline group of 0 -to-4 years), I find that durability has a significant negative effect on FGM for all dummies: a political regime existing for 5-to-10 years leads to a 0.07-standard-deviation larger decrease in the share of newly-circumcised women. The magnitude of the effect almost triples for regimes that last longer: a political regime lasting more than 10 years leads to a 0.19 -standard-deviation larger decrease in the share of newly-circumcised women. Moreover, the magnitude of the coefficient does not change for any of the other two dummy variables of regime durability. ${ }^{35}$ This result suggests that $5-10$ years is enough for people to start to believe that a regime will continue to fight against FGM; however, regimes lasting longer than 10 years have the same effect.

\footnotetext{
${ }^{35}$ Coefficients for three indicator variables (11-to-15, 16-to-20, and more than 20 years of durability) do not reject the joint equality t-test.
} 


\section{B.2 Subsample Analysis}

Table B.2: Impact of Regime Durability on FGM: Subsamples

\begin{tabular}{|c|c|c|c|c|c|c|}
\hline \multirow[b]{3}{*}{ Sample } & I & II & III & IV & $\mathrm{V}$ & VI \\
\hline & \multicolumn{6}{|c|}{ Dependent variable: Share of newly circumcised women } \\
\hline & Baseline & Only Africa & Not MENA & $\begin{array}{l}\text { Partitioned } \\
\text { ethnicities }\end{array}$ & Rural & Urban \\
\hline Durability & $\begin{array}{c}-0.084^{* *} \\
(0.036)\end{array}$ & $\begin{array}{l}-0.079^{*} \\
(0.039)\end{array}$ & $\begin{array}{l}-0.070^{*} \\
(0.038)\end{array}$ & $\begin{array}{c}-0.090 * * \\
(0.037)\end{array}$ & $\begin{array}{c}-0.059^{* *} \\
(0.024)\end{array}$ & $\begin{array}{c}-0.132 * * \\
(0.055)\end{array}$ \\
\hline$\#$ of clusters & 23 & 20 & 19 & 22 & 23 & 23 \\
\hline R-squared & 0.483 & 0.494 & 0.506 & 0.510 & 0.386 & 0.598 \\
\hline Observations & 6,161 & 6,108 & 6,000 & 1,362 & 3,849 & 3,849 \\
\hline
\end{tabular}

Notes: This table uses the most conservative specification in Table 1, Panel A, Column IX. Northern Yemen, Southern Yemen, and Iraq are excluded in Column II. Column III has the sample as in Column II but without Egypt. The sample in Column IV includes only ethnic groups that appear in more than one country. I exclude all respondends living in urban (rural) areas in Column V (VI). All regressions contain constants, country-ethnicity, and time fixed effects. Robust clustered by country standard errors are in parentheses. ${ }^{* * *} \mathrm{p}<0.01,{ }^{* *} \mathrm{p}<0.05,{ }^{*} \mathrm{p}<0.1$

First, in Table B.2, I show that the size of the coefficient is not driven by Middle Eastern countries where the tradition of FGM is strong. Column I contains results of the same regression specification as Column IX in Panel A of Table 1, and these figures are provided for comparison. To show that results are not driven by countries outside the African continent, I exclude Iraq and Yemen in Column II. ${ }^{36}$ The negative effect of regime durability doesn't change appreciably and remains significant. In Column III, I drop all countries belonging to the Middle East and North Africa; while the magnitude drops, it remains significant.

The next concern is that ethnic groups that are unique to certain countries do not contribute to the identification of the effect of regime stability. In Column IV, I limit the sample to ethnic groups that live in more than one country. The negative effect remains,

\footnotetext{
${ }^{36}$ Yemen is counted as two countries (North Yemen and South Yemen) before 1990.
} 
while the significance falls slightly.

I also check whether results differ if I use only rural or urban subsamples of women (Columns V and VI). One may say that traditions are stronger in rural areas. However, anthropologists and sociologists suggest that in urban areas the marriage market is small and the benefit from FGM is higher. ${ }^{37}$ Both coefficients of interest are significant, and the effect of regime stability is more than twice as large for the urban sub-sample, thus suggesting that supporting importance of FGM the later argument. ${ }^{38}$

\footnotetext{
${ }^{37}$ Mackie and LeJeune (2009) and UNICEF (2013) point out that marriage markets in African countries are very narrow; they are limited not only by ethnic group identity but also by smaller regional tribal identity or even kinship. It is very common that marriage markets are bounded by the size of the family, since men marry their cousins because they have more information about family members than women who are not from their families. In addition, in patriarchal societies, it is often forbidden to marry cousins from the father's side but not from the mother's side, since they do not count blood ties from the mother's line. In this case, women in urban areas will have an even smaller pool of marriage partners, since they will be surrounded by people from different ethnic groups that cannot be considered in the marriage market, and they will have fewer eligible men from their rural homelands whom they could potentially marry.

${ }^{38}$ Another alternative explanation can be that if FGM rates in rural areas are close to zero, thus the effect of regime stability is smaller due to the "floor" effect. However, FGM rates in rural area are quite high, thus ruling out this hypothesis.
} 


\section{B.3 Dynamic Panel}

In the case of serial correlation of the dependent variable, it may be important to control the lagged dependent variable on the right-hand side of specification 3.1. For example, if too many women were circumcised at year $t-1$, then there will be fewer eligible women in year $t$. Then there will be a mechanical relationship between the dependent variable at time $t$ and $t-1$ because the stock of eligible women goes down; hence it takes only a small absolute number of women undergoing FGM in year $t$ to also get a large $\operatorname{fgm}_{\text {cet }}$.

If I add a lagged dependent variable and it is correlated with the unobserved panellevel effects, my estimates will be inconsistent. The logical choice to alleviate this concern is to use the Blundell-Bond estimator (Blundell and Bond, 1998) ${ }^{39}$ The result, shown in Column I of Table B.3, is consistent with other estimates.

\footnotetext{
${ }^{39}$ For this, I assume that there are no autocorrelations in the idiosyncratic errors and that the panel-level effects are uncorrelated with the first difference of the first observation of the dependent variable $\left(f g m_{e c t}\right)$.
} 


\begin{tabular}{lc}
\hline & I \\
\hline & Dependent Variable: \\
\hline \hline & Share of newly circumcised women \\
\hline Durability & $-0.135^{* * *}$ \\
& $(0.0202)$ \\
Share of & $-0.173^{* * *}$ \\
circumcised women L1 & $(0.021)$ \\
Durability L1 & 0.019 \\
& $(0.019)$ \\
Observations & 3,828 \\
\hline \hline
\end{tabular}

Notes: This table uses the most conservative specification in Table 1, Panel A, Column IX. Column I is estimated using two-step Blundell-Bond Dynamic Panel estimation. Lagged differences of $\mathrm{fgm}_{\text {ect }}$ and Durabilityct are taken as instruments. In addition, Durabilityct L2 is used as controls. Robust GMM standard errors are in parentheses for Column I. ${ }^{* * *} \mathrm{p}<0.01,{ }^{* *} \mathrm{p}<0.05,{ }^{*} \mathrm{p}<0.1$ 


\section{B.4 Exploring Individual-Level Data}

In Columns II and III of Table 2, I exploit individual-level data. By doing this, I am able to account for different values of regime stability throughout women's lifetimes. I provide an empirical specification, aiming to identify the probability that a woman will be circumcised due to changes in regime durability. Using the Cox Proportional Hazard model, I estimate the length of time before the "failure event" (FGM in this specification) using a baseline hazard function. It uses individual-level data that are organized in person-year panel data. ${ }^{40}$ As FGM is permanent, we can consider women's states of the world as a Markov chain, where "no FGM" is a transitional state, and "FGM" is an absorbing state. ${ }^{41}$ The duration of interest for each woman $i$ is the time between $t_{0}$, when she becomes eligible for circumcision, and $t_{T}$, the age when she has either undergone circumcision or has become ineligible due to age. In this case, if a woman is not circumcised, she contributes $t_{T}-t_{0}$ number of observations, while if she is circumcised at year $s$, she contributes $s-t_{0}$ observations.

I present the Cox duration model in Column II. Durability of the regime and the interaction term of democracy and regime durability are both negative and significant, thus corroborating my hypothesis. Thus, in a 11-year-old autocratic regime, Durabilityct leads to a $3.8 \%$ decrease in the probability of women being circumcised in any given year of

\footnotetext{
${ }^{40}$ I do not use a linear probability model or probit due to obvious autocorrelation of the observation for the same woman in different years of her life. Nevertheless, these results are consistent with other results and are available upon request.

${ }^{41} \mathrm{~A}$ similar approach is implemented in studies about male circumcision (Venkataramani and MaughanBrown, 2013), death and terminal cancer (Honoré and Lleras-Muney, 2006), and HIV (Burke, Gong and Jones, 2015).
} 
woman's life when she is eligible for circumcision.

In addition to region, ethnicity, religion, and year fixed effects, thanks to the thoroughness of the questionnaire a number of variables account for most of the unobserved heterogeneity concerns. To control for variables that might correlate with regime durability, in addition to the controls for the baseline specification 3.1, I add dummies for households assets, such as land, type of roof, and floor. ${ }^{42}$ These variables should catch the effects of institutions and regime stability through possible land-ownership legislation or assets expropriation.

Clearly, use of individual-level data will suffer from serial correlation due to the nature of FGM tradition. Because observations are likely to be temporally correlated due to duration dependence or possible nonlinearity of the trend, traditional techniques pose problems. To address this, following Beck, Katz and Tucker (1998), I include a natural cubic spline function of the number of years a female has been without FGM in all individual-level estimations.

To better control for the unobservable heterogeneity of individual data, in Column III, I present an alternative estimation method using conditional logit estimation (Chamberlain, 1980). Conditional logit can provide unbiased estimates of the parameters, but only for the subsample of individuals who were circumcised during the observed period. The odds ratio for regime durability is significant and below unity, such that a

\footnotetext{
${ }^{42}$ Since I use person-year panel data constructed from the surveys that provide a snapshot of the household's information in a given year but not the years of life in which women were eligible for circumcision, use of a wealth index at the time of the survey could have been misleading. At the same time, assets such as land and houses are often hereditary and thus contain less measurement error, since they do not change appreciably over time.
} 
B.4 Exploring Individual-Level Data Online Appendix - Not for Publication one-year increase in regime durability leads to a 12.8 percent decrease in the odds of being circumcised. The effect is much stronger here, as here we consider only the sample of circumcised women. 
B.5 Robustness to Alternative Measures of Regin@entinerałpipitgndix - Not for Publication B.5 Robustness to Alternative Measures of Regime Durability

Table B.4: Alternative Measures of Regime Durability

\begin{tabular}{|c|c|c|c|c|c|}
\hline \multirow{4}{*}{$\begin{array}{l}\text { Measure of durability: } \\
\text { Durability }\end{array}$} & I & II & III & IV & $\mathrm{V}$ \\
\hline & \multicolumn{5}{|c|}{ Dependent variable: Share of newly circumcised women } \\
\hline & Polity & PDI & FHPI & GWF & PCA \\
\hline & $\begin{array}{c}-0.084^{* *} \\
(0.036)\end{array}$ & $\begin{array}{c}-0.063^{* *} \\
(0.028)\end{array}$ & $\begin{array}{c}-0.063^{* *} \\
(0.030)\end{array}$ & $\begin{array}{c}-0.061^{* *} \\
(0.028)\end{array}$ & $\begin{array}{c}-0.339^{* *} \\
(0.151)\end{array}$ \\
\hline R-squared & 0.48 & 0.54 & 0.54 & 0.544 & 0.544 \\
\hline Observations & 6,161 & 3,920 & 3,920 & 3,920 & 3,920 \\
\hline
\end{tabular}

Notes: This table uses the most conservative specification in Table 1, Panel A, Column IX but uses alternative measures of regime durability. Robust standard errors clustered by country are in parentheses. ${ }^{* * *} \mathrm{p}<0.01$, ${ }^{* *} \mathrm{p}<0.05,{ }^{*} \mathrm{p}<0.1$ 


\section{B.6 Robustness to Changes in National Leadershplind Regiemelixhangesfor Publication $\overline{\text { B.6 Robustness to Changes in National Leadership and Regime Changes }}$}

Table B.5: Robustness to Changes in National Leadership and Regime Changes

\begin{tabular}{|c|c|c|c|c|c|c|c|}
\hline & $\mathrm{I}$ & II & III & IV & V & VI & VII \\
\hline & \multicolumn{7}{|c|}{ Dependent variable: Share of newly circumcised women } \\
\hline & Baseline & $\begin{array}{c}\text { New national } \\
\text { leader }\end{array}$ & $\begin{array}{l}\text { Regime } \\
\text { changes }\end{array}$ & $\begin{array}{l}\text { w/o years of } \\
\text { regime } \\
\text { changes }\end{array}$ & $\begin{array}{l}\text { New political } \\
\text { regime }\end{array}$ & $\begin{array}{c}\text { Violence } \\
\text { after regime } \\
\text { change }\end{array}$ & $\begin{array}{c}\text { Type of } \\
\text { authoritarian } \\
\text { regime }\end{array}$ \\
\hline Durability & $\begin{array}{c}-0.084 * * \\
(0.036)\end{array}$ & $\begin{array}{l}-0.070^{*} \\
(0.037)\end{array}$ & $\begin{array}{c}-0.086 * * \\
(0.036)\end{array}$ & $\begin{array}{c}-0.087 * * \\
(0.038)\end{array}$ & $\begin{array}{c}-0.085^{* *} \\
(0.036)\end{array}$ & $\begin{array}{c}-0.086^{* *} \\
(0.036)\end{array}$ & $\begin{array}{c}-0.090^{* *} \\
(0.043)\end{array}$ \\
\hline 1(New national leader) & & $\begin{array}{l}-1.01^{*} \\
(0.550)\end{array}$ & & & & & \\
\hline 1(Regime change) & & & $\begin{array}{l}-0.418 \\
(0.529)\end{array}$ & & & & \\
\hline 1 (Transition to democracy) & & & & & $\begin{array}{l}0.603 * \\
(0.345)\end{array}$ & & \\
\hline 1(Transition to dictatorship) & & & & & $\begin{array}{c}-1.401 * * \\
(0.611)\end{array}$ & & \\
\hline 1(Transition to failed state) & & & & & $\begin{array}{l}1.302 * \\
(0.660)\end{array}$ & & \\
\hline 1(Violence after regime change) & & & & & & $\begin{array}{l}-0.277 \\
(0.252)\end{array}$ & \\
\hline 1(Party regime) & & & & & & & $\begin{array}{c}-1.589 * * \\
(0.666)\end{array}$ \\
\hline 1(Personality regime) & & & & & & & $\begin{array}{c}0.628 \\
(0.853)\end{array}$ \\
\hline R-squared & 0.483 & 0.495 & 0.483 & 0.463 & 0.484 & 0.484 & 0.495 \\
\hline Observations & 6,161 & 6,161 & 6,161 & 5,857 & 6,161 & 6,161 & 6,161 \\
\hline
\end{tabular}

Notes: This table uses the most conservative specification in Table 1, Panel A, Column IX but with additional controls. Robust standard errors clustered by country are in parentheses. ${ }^{* *} \mathrm{p}<0.01,{ }^{* *} \mathrm{p}<0.05,{ }^{*} \mathrm{p}<0.1$ 


\section{B.7 Health Outcomes, Education, and EmpoweromehinefAptperredix - Not for Publication B.7 Health Outcomes, Education, and Empowerment of Women}

Table B.6: Health Outcomes, Education, and Empowerment of Women

\begin{tabular}{|c|c|c|c|c|c|c|c|}
\hline & I & II & III & IV & $\mathrm{V}$ & VI & VII \\
\hline & \multicolumn{7}{|c|}{ Dependent variable: } \\
\hline & $\begin{array}{l}\text { Infant } \\
\text { mortality }\end{array}$ & HIV & $\begin{array}{c}\text { Life } \\
\text { expectancy }\end{array}$ & Fertility & Education & $\begin{array}{l}\text { Medical } \\
\text { provision }\end{array}$ & $\begin{array}{c}\text { Gov. } \\
\text { empowering } \\
\text { women }\end{array}$ \\
\hline Data & \multicolumn{5}{|c|}{ Baseline (DHS \& MICS) } & \multicolumn{2}{|c|}{ Afrobarometer } \\
\hline Durability & $\begin{array}{c}0.002 \\
(0.010)\end{array}$ & $\begin{array}{c}0.032 \\
(0.062)\end{array}$ & $\begin{array}{l}-0.004 \\
(0.007)\end{array}$ & $\begin{array}{c}0.008 \\
(0.024)\end{array}$ & $\begin{array}{c}0.011 \\
(0.045)\end{array}$ & $\begin{array}{c}0.038 \\
(0.024)\end{array}$ & $\begin{array}{l}-0.004 \\
(0.009)\end{array}$ \\
\hline R-squared & 0.938 & 0.937 & 0.894 & 0.963 & 0.963 & 0.339 & 0.251 \\
\hline Observations & 6,182 & 2,611 & 6,208 & 3,158 & 6,216 & 54 & 54 \\
\hline
\end{tabular}

Notes: This table uses the most conservative specification in Table 1, Panel A, Column IX, but employes alternative outcome variables. The dependent variable in Column I (infant mortality) is the number of deaths per 1,000 infants. The dependent variable in Column II is Prevalence of HIV, \%. The dependent variable in Column III is log of life expectancy. The dependent variable in Column IV (fertility) is a total number of births per woman. Robust clustered by country standard errors are in parentheses. ${ }^{* * *} \mathrm{p}<0.01$, ${ }^{* *} \mathrm{p}<0.05,{ }^{*} \mathrm{p}<0.1$ 
B.8 Alternative Coding of Anti-FGM Laws Online Appendix - Not for Publication B.8 Alternative Coding of Anti-FGM Laws

Table B.7: Robustness of the Results to the Various Types of Anti-FGM Laws and Policies

\begin{tabular}{|c|c|c|c|c|c|c|c|c|c|c|}
\hline & II & II & III & IV & 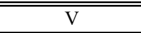 & VI & VII & "VIII & IX & 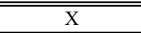 \\
\hline & \multicolumn{10}{|c|}{ Dependent variable: Share of newly circumcised women } \\
\hline Interaction & $\begin{array}{c}\text { Baseline / Any } \\
\text { law }\end{array}$ & $\begin{array}{l}\text { Clear definition } \\
\text { of FGM }\end{array}$ & $\begin{array}{c}\text { Criminalises the } \\
\text { performance of } \\
\text { FGM }\end{array}$ & $\begin{array}{c}\text { Crim. the } \\
\text { procurement, } \\
\text { arrangement or } \\
\text { assistance of } \\
\text { FGM }\end{array}$ & $\begin{array}{c}\text { Criminalises the } \\
\text { failure to report } \\
\text { incidents of } \\
\text { FGM }\end{array}$ & $\begin{array}{l}\text { Crim. the } \\
\text { participation of } \\
\text { medics in acts of } \\
\text { FGM }\end{array}$ & $\begin{array}{l}\text { Criminalises the } \\
\text { practice of cross- } \\
\text { border FGM }\end{array}$ & $\begin{array}{l}\text { \# of legislations } \\
\text { for Columns II- } \\
\text { VII (0 to } 6)\end{array}$ & $\begin{array}{c}\text { PCA for } \\
\text { Columns II-VII }\end{array}$ & $\begin{array}{c}\text { Government has } \\
\text { a strategy in } \\
\text { place to end } \\
\text { FGM }\end{array}$ \\
\hline Durability & $\begin{array}{l}-0.015 \\
(0.018)\end{array}$ & $\begin{array}{l}-0.012 \\
(0.018)\end{array}$ & $\begin{array}{l}-0.011 \\
(0.019)\end{array}$ & $\begin{array}{l}-0.029 \\
(0.034)\end{array}$ & $\begin{array}{l}-0.038 \\
(0.028)\end{array}$ & $\begin{array}{l}-0.039 \\
(0.029)\end{array}$ & $\begin{array}{l}-0.035 \\
(0.024)\end{array}$ & $\begin{array}{l}-0.020 \\
(0.026)\end{array}$ & $\begin{array}{l}-0.031 \\
(0.023)\end{array}$ & $\begin{array}{l}-0.017 \\
(0.017)\end{array}$ \\
\hline Durability x Interaction & $\begin{array}{l}-0.053^{* *} \\
(0.022)\end{array}$ & $\begin{array}{l}-0.052 * * \\
(0.022)\end{array}$ & $\begin{array}{c}-0.054 * * \\
(0.019)\end{array}$ & $\begin{array}{l}-0.022 \\
(0.032)\end{array}$ & $\begin{array}{l}-0.001 \\
(0.028)\end{array}$ & $\begin{array}{l}0.003 \\
(0.032)\end{array}$ & $\begin{array}{l}-0.152 \\
(0.131)\end{array}$ & $\begin{array}{c}-0.009 * * \\
(0.004)\end{array}$ & $\begin{array}{c}-0.007 * \\
(0.003)\end{array}$ & $\begin{array}{c}-0.050^{*} \\
(0.026)\end{array}$ \\
\hline Interaction & $\begin{array}{l}1.219^{*} \\
(0.636)\end{array}$ & $\begin{array}{c}0.255 \\
(1.578)\end{array}$ & $\begin{array}{l}0.133 \\
(1.104)\end{array}$ & $\begin{array}{l}-0.444 \\
(0.839)\end{array}$ & $\begin{array}{c}0.817 \\
(1.685)\end{array}$ & $\begin{array}{l}-0.437 \\
(1.342)\end{array}$ & $\begin{array}{l}2.932 * * \\
(1.355)\end{array}$ & $\begin{array}{c}0.559 * * \\
(0.205)\end{array}$ & $\begin{array}{l}2.222 * * \\
(0.915)\end{array}$ & $\begin{array}{l}1.448 \\
(0.879)\end{array}$ \\
\hline $\begin{array}{l}\text { R-squared } \\
\text { Observations }\end{array}$ & $\begin{array}{l}0.596 \\
6,161\end{array}$ & $\begin{array}{l}0.596 \\
6,161\end{array}$ & $\begin{array}{l}0.596 \\
6,161\end{array}$ & $\begin{array}{l}0.596 \\
6,161\end{array}$ & $\begin{array}{l}0.596 \\
6,161\end{array}$ & $\begin{array}{l}0.596 \\
6,161\end{array}$ & $\begin{array}{l}0.596 \\
6,161\end{array}$ & $\begin{array}{l}0.596 \\
6,161\end{array}$ & $\begin{array}{l}0.596 \\
6,161\end{array}$ & $\begin{array}{l}0.596 \\
6,161\end{array}$ \\
\hline
\end{tabular}

Notes: This table uses the specification from Column II of Table 3, but uses alternative anti-FGM laws.

Robust clustered by country standard errors are in parentheses. ${ }^{* * *} \mathrm{p}<0.01,{ }^{* *} \mathrm{p}<0.05,{ }^{*} \mathrm{p}<0.1$ 
B.9 Expectations about Government Online Appendix - Not for Publication B.9 Expectations about Government

Table B.8: Regime Durability and Expectations about Government

\begin{tabular}{lc}
\hline \hline & \multicolumn{1}{c}{$\mathrm{I}$} \\
\cline { 2 - 2 } Dependent variable: & $\begin{array}{c}\text { Expectation gov. } \\
\text { will solve } \\
\text { problems }\end{array}$ \\
\cline { 2 - 2 } Durability & $0.002 * *$ \\
& $(0.001)$ \\
R-squared & 0.171 \\
Observations & 34 \\
\hline \hline
\end{tabular}

Notes: All regressions contain constants and time fixed effects. The following variables are used as controls: polity score and executive constraint score. Robust standard errors are in parentheses. ${ }^{* * *} \mathrm{p}<0.01,{ }^{* *} \mathrm{p}<0.05$, ${ }^{*} \mathrm{p}<0.1$ 
B.10 Confounding Institutional Effects

\section{B.10 Confounding Institutional Effects}

Table B.9: Regime Durability and Confounding Institutional Effects

\begin{tabular}{|c|c|c|c|c|c|c|c|c|c|}
\hline & I & II & III & IV & $\mathrm{V}$ & VI & VII & VIII & IX \\
\hline & \multicolumn{9}{|c|}{ Dependent variable: Share of newly circumcised women } \\
\hline & Baseline & $\begin{array}{l}\text { Executive } \\
\text { constraints }\end{array}$ & $\begin{array}{c}\text { ANRR } \\
\text { dem. Index }\end{array}$ & Revolution & $\begin{array}{l}\text { Gov. } \\
\text { crises }\end{array}$ & $\begin{array}{l}\text { Anti-gov. } \\
\text { demonstr. }\end{array}$ & Civil war & & \\
\hline Durability & $\begin{array}{l}-0.08^{*} \\
(0.036)\end{array}$ & $\begin{array}{l}-0.07^{*} \\
(0.037)\end{array}$ & $\begin{array}{l}-0.07^{*} \\
(0.036)\end{array}$ & $\begin{array}{l}-0.08^{*} \\
(0.037)\end{array}$ & $\begin{array}{l}-0.07^{*} \\
(0.036)\end{array}$ & $\begin{array}{l}-0.07^{*} \\
(0.036)\end{array}$ & $\begin{array}{l}-0.07^{*} \\
(0.036)\end{array}$ & $\begin{array}{c}-0.08 * * \\
(0.038)\end{array}$ & $\begin{array}{c}-0.08^{* *} \\
(0.038)\end{array}$ \\
\hline Executive constraints & & $\begin{array}{l}-0.08 \\
(0.245)\end{array}$ & & & & & & $\begin{array}{c}-0.17 \\
(0.231)\end{array}$ & $\begin{array}{c}-0.21 \\
(0.235)\end{array}$ \\
\hline ANRR dem. index & & & $\begin{array}{c}0.97 \\
(0.790)\end{array}$ & & & & & $\begin{array}{c}1.24 \\
(0.742)\end{array}$ & $\begin{array}{c}1.38^{*} \\
(0.726)\end{array}$ \\
\hline Revolution & & & & $\begin{array}{l}-0.30 \\
(0.192)\end{array}$ & & & & $\begin{array}{l}-0.28 \\
(0.215)\end{array}$ & $\begin{array}{l}-0.29 \\
(0.208)\end{array}$ \\
\hline Gov. crises & & & & & $\begin{array}{l}-0.33 \\
(0.307)\end{array}$ & & & $\begin{array}{l}-0.15 \\
(0.345)\end{array}$ & $\begin{array}{l}-0.12 \\
(0.365)\end{array}$ \\
\hline Ant-gov. demonstrations & & & & & & $\begin{array}{l}-0.08 \\
(0.079)\end{array}$ & & $\begin{array}{c}-0.03 \\
(0.082)\end{array}$ & $\begin{array}{c}0.03 \\
(0.104)\end{array}$ \\
\hline Civil war & & & & & & & $\begin{array}{c}0.20 \\
(0.356)\end{array}$ & $\begin{array}{c}0.27 \\
(0.351)\end{array}$ & $\begin{array}{c}0.40 \\
(0.333)\end{array}$ \\
\hline Additional inst. controls & & & & & & & & & $\checkmark$ \\
\hline R-squared & 0.495 & 0.495 & 0.495 & 0.495 & 0.495 & 0.495 & 0.495 & 0.496 & 0.496 \\
\hline Observations & 6,161 & 6,161 & 6,161 & 6,161 & 6,161 & 6,161 & 6,161 & 6,161 & 6,161 \\
\hline
\end{tabular}

Notes: This table uses the most conservative specification in Table 1, Panel A, Column IX but includes additional controls. Additional institutional controls in Column IX include: dummy for international war, number of political assassinations, riots, strikes, purges, guerrilla warfare, and the weighted conflict measure. Robust clustered by country standard errors are in parentheses. ${ }^{* * *} \mathrm{p}<0.01,{ }^{* *} \mathrm{p}<0.05,{ }^{*} \mathrm{p}<0.1$

Column I of Table B.9 contains the baseline regression specification from Column IX of Table 1. Then in Columns II-VIII, I add, one by one, additional institutional controls that may confound my findings on regime durability and FGM. In Column II, following Acemoglu and Johnson (2005), I add a control for the "constraint on executive" measure from the Polity IV dataset as a property-rights-institutions control. As executive constraint can correlate with state capacity to enforce anti-FGM laws imposed by the government, it can be an important source of omitted-variable bias. My results also hold in Column III, where I include the binary democracy indicator from Acemoglu et al. (2014). I add indicator variables for revolutions, government crises, and number of antigovernmental 

demonstrations in Columns IV, V, and VI; my results still hold. ${ }^{43}$ I also add a dummy for civil wars in Column VII. Including each of the aforementioned confounding institutional controls did not affect the coefficient of interest.

In Column VIII, I add all these institutional controls; taken together, they do not affect the significance of the coefficient for regime durability, which even increased in magnitude. Finally, I add additional institutional controls (for political assassinations, riots, strikes, purges, guerrilla warfare, and the weighted conflict measure from Banks and Wilson (2016)) in Column IX; controls do not affect the coefficient for regime durability. My results suggest that other country-year institutional variables seem to have no robust effect on FGM.

To sum up, regime durability remains significant regardless of the set of control variables for national institutions, revealing that regime durability's effect on FGM rates is not confounded by state capacity or institutional factors. The results suggest that the effect of regime durability on FGM is not associated with the security concept of state capacity articulated by Besley and Persson (2011) or any other institutional characteristics. Thus, regime durability appears to capture people's evaluation of how durable the current political regime is, as they do not want to stop circumcising their daughters if they are not sure whether the FGM policy will stop with a regime change.

\footnotetext{
${ }^{43}$ Data for these variables come from Banks and Wilson (2016). Similarly, results hold if I control for government crises, failed states, and in-turmoil regimes. Probably the best way to control for state capacity is to use the same measures as Besley and Persson (2011); however, due to the cross-sectional structure of the data, I cannot control for the state's ability to collect taxes and enforce contracts. One way to account for this is to use the State Fragility Index developed by Polity IV or the Mo Ibrahim Index of African Governance, developed by the Mo Ibrahim Foundation; however, these have been available only since 1995 and 2000, respectively, thus decreasing variation in the main variable of interest. Such important controls as legal origin, corruption, trust, and strength of the local chieftains should be accounted for by fixed effects.
} 
B.11 Confounding Economic Factors

Online Appendix - Not for Publication

\section{B.11 Confounding Economic Factors}

Table B.10: Regime Durability and Country-Specific Economic Factors

\begin{tabular}{|c|c|c|c|c|c|c|}
\hline & $\mathrm{I}$ & II & III & IV & $\mathrm{V}$ & VI \\
\hline & \multicolumn{6}{|c|}{ Dependent variable: Share of newly circumcised women } \\
\hline & Baseline & $\begin{array}{l}\text { Share of } \\
\text { export in } \\
\text { GDP }\end{array}$ & $\begin{array}{l}\text { Share of } \\
\text { import in } \\
\text { GDP }\end{array}$ & $\begin{array}{l}\text { Trade-to- } \\
\text { GDP ratio }\end{array}$ & $\begin{array}{c}\text { Trade- } \\
\text { weighted } \\
\text { tariffs }\end{array}$ & All \\
\hline Durability & $\begin{array}{c}-0.084 * * \\
(0.036)\end{array}$ & $\begin{array}{c}-0.084 * * \\
(0.036)\end{array}$ & $\begin{array}{c}-0.087 * * \\
(0.037)\end{array}$ & $\begin{array}{c}-0.082 * * \\
(0.034)\end{array}$ & $\begin{array}{c}-0.084 * * \\
(0.036)\end{array}$ & $\begin{array}{c}-0.087 * * \\
(0.036)\end{array}$ \\
\hline Share of export in GDP & & $\checkmark$ & & & & $\checkmark$ \\
\hline Share of import in GDP & & & $\checkmark$ & & & $\checkmark$ \\
\hline Trade-to-GDP ratio & & & & $\checkmark$ & & $\checkmark$ \\
\hline Trade-weighted tariffs & & & & & $\checkmark$ & $\checkmark$ \\
\hline R-squared & 0.483 & 0.484 & 0.486 & 0.483 & 0.963 & 0.487 \\
\hline Observations & 6,161 & 6,161 & 6,161 & 6,161 & 6,216 & 6,161 \\
\hline
\end{tabular}

Notes: This table uses the most conservative specification in Table 1, Panel A, Column IX but includes additional controls. Robust clustered by country standard errors are in parentheses. ${ }^{* *} \mathrm{p}<0.01,{ }^{* *} \mathrm{p}<0.05$, * $\mathrm{p}<0.1$ 
B.12 Selection on Unobservables

Online Appendix - Not for Publication

\section{B.12 Selection on Unobservables}

Despite the rich set of control variables, some unobserved heterogeneity may still bias the effect of regime stability if omitted variables are correlated with both FGM prevalence and regime durability. To alleviate the concern about the effect of unobservables, in the following subsection I evaluate the likelihood that the coefficient estimates are biased by omitted variables.

This approach is aimed at measuring the strength of the likely bias caused by a possible omitted variable. To do this, I estimate the coefficient for regime durability in two regressions, one with a full set of controls ( $\hat{\beta}^{U R}$ ) (I use Column III of Table 1) and one that is restricted and uses fewer or no controls $\left(\hat{\beta}^{R}\right)$. We are interested in the coefficient of proportionality $\frac{\hat{\beta}^{U R}}{\hat{\beta}^{R}-\hat{\beta}^{U R}}$, which basically shows how much larger the effect of unobservables should be in order to explain the coefficient of interest in unrestricted regression. On one hand, a larger $\hat{\beta}^{U R}$ in the numerator means that the effect of the omitted variable should also be larger in order to explain it away. On the other hand, the smaller the difference

seen in $\left(\hat{\beta}^{R}-\hat{\beta}^{U R}\right)$, the smaller the effect of regime stability affected by the selection on observables, and thus the selection in unobservables should be larger as well. The larger the ratio, the greater the effect of omitted variables should be in order to bias my results, thus making it less likely to happen.

I consider three sets of controls for the restricted regression: one without controls; one with controls for democracy and terrorist severity; and one with controls for religion, polygamy, marriage-market size, and attitude toward FGM. In addition to the baseline 

specification with the Polity IV measure of regime durability, I use PCA of other measures provided in Table B.9. I provide the ratios for all measures of regime stability in Table B.11. The ratios range from 2.5 to 3.5 , with mean and median equal to 2.7. This means that, in order to claim that the OLS estimate of the effect of regime stability is fully driven by omitted variables, selection on unobservables would have to be at least 2.6 times greater than selection on observables to explain away the full estimated effect. In other words, it is very unlikely that the estimated effect of regime stability is fully driven by unobservables.

Nevertheless, the approach above can result in too optimistic values of the coefficient of proportionality as was shown in Oster (2017). To address this concern, I employ the procedure proposed in Oster (2017), in which she relaxes the assumption of equal selection and replaces it with a not necessarily equal proportional selection relationship. Her approach is similar to the one developed by Altonji, Elder and Taber (2005), in that she argues that unobservables should not be more important than the observables in explaining the treatment. At the same time, she suggests adopting the conservative bounding value for the R-squared $\left(\overline{R_{\max }}\right)$ from the hypothetical regression with all observable and unobservables controls all together, and then finding the value of the coefficient of proportionality $(\delta)$ for which the estimator would produce a treatment effect of zero. Thus, intuitively, the coefficient of interest can be expressed as a function of $\delta$ and R-squared movements $\left(\beta=\beta\left(\delta, \overline{R_{\max }}\right)\right.$ ), and by setting $\beta=0$ we can calculate how big the effect of unobservables $\delta$ given $\overline{R_{\max }}$ should be. This approach is better then the one provided in panel $\mathrm{A}$, as it assumes that unobservables explain as much as observables 
B.12 Selection on Unobservables

Online Appendix - Not for Publication $\left.\overline{\left(R_{\max }\right.}=R^{U R}+\left(R^{U R}-R^{R}\right)\right)$, where $R^{U R}$ is a $R^{2}$ of the unrestricted regression with full set of controls, and $R^{R}$ corresponds to the $R^{2}$ from restricted regression without any controls. Due to small changes in R-squared after adding control variables, $\overline{R_{\max }}$ can be too low, thus resulting in bigger values of the coefficient of proportionality $\delta$.

Table B.11: Using Selection on Observables to Assess the Bias from Unobservables Panel A

\begin{tabular}{ccc}
\hline & \multicolumn{3}{c}{ Durability } \\
Controls in the restricted set & (I) Polity IV & (II) PCA \\
\hline \hline None & -2.50 & -3.13 \\
Democracy, terrorist severity & -2.83 & -3.49 \\
Religion, polygamy, marriage-market size, attitude toward FGM & -2.65 & -3.14 \\
\hline \hline Panel B & \multicolumn{2}{c}{ Durability } \\
\hline \multirow{2}{*}{ Controls in the restricted set } & (I) Polity IV & (II) PCA \\
\hline \hline None & 1.16 & 1.11 \\
$R_{\max }$ & 0.59 & 0.59 \\
\hline \hline
\end{tabular}

Notes: Regime durability in Column I is a variable durable from the Polity IV; durability in Column II is computed as in the first principal component of the Polity scores. See section 4 for more information about PCA. Each cell of Panel A reports ratios based on the coefficient for measure of regime durability from two regressions with specification 3.1. The first regression includes the "restricted set" of control variables and results in coefficient $\hat{\beta}^{R}$. The second includes the "full set" of controls and results in the coefficient $\hat{\beta}^{U R}$. In both regressions, the sample sizes are the same and fixed effects are included. The reported ratio is calculated as follows: $\hat{\beta}^{U R} /\left(\hat{\beta}^{R}-\hat{\beta}^{U R}\right)$. First row in Panel B reports the coefficient of proportionality $\delta$ computed by using psacalc STATA code (Oster (2017)). The $\overline{R_{\max }}$ is computed as $1.3 R^{U R}$, where $R^{U R}$ is an R-squared of the regression with the full set of controls. See Table 1 for a description of the full set of controls.

Results of the robustness test are shown in panel B of Table B.11. As in panel A, I show results for three measures of regime durability; however, this time I consider only the specification with no control variables and report $\delta$ for different values of $\overline{R_{\max }}$. Following Oster (2017) I use value of $\overline{R_{\max }}=1.3 R^{U R}$. For the baseline specification in Table $1, R^{U R}=0.45$, thus $\overline{R_{\max }}=0.59 .^{44}$ The value of $\delta$ for the Polity IV regime durability

\footnotetext{
${ }^{44} \overline{R_{\max }}>0.55$ for all columns. According to UNICEF (2013), ethnicity explains up to $55 \%$ of the variation
} 

measure suggests that the unobservables would need to be 1.2 times as important as the observables to completely explain away the effect of political regime stability. Similarly, all other values of $\delta$ are above 1 , suggesting that my results are robust.

in FGM, and my observation is on country-ethnicity level, making it a logical choice for the appropriate $\overline{R_{\max }}$. 
B.13 Regime Durability and Ethnic Identity Online Appendix - Not for Publication B.13 Regime Durability and Ethnic Identity

Table B.12: Regime Durability, Ethnic Identity, and Religious Identity

\begin{tabular}{lcc}
\hline \hline & I & II \\
\cline { 2 - 3 } Dependent variable: & Ethnic identity & Religiosity \\
\cline { 2 - 3 } & & \\
\cline { 2 - 3 } Durability & -0.003 & 0.011 \\
& $(0.003)$ & $(0.016)$ \\
R-squared & 0.295 & 0.202 \\
Observations & 88 & 68 \\
\hline \hline
\end{tabular}

Notes: All regressions contain constants and time fixed effects. The following variables are used as controls: polity score and executive constraint score. Robust standard errors are in parentheses. ${ }^{* *} \mathrm{p}<0.01,{ }^{* *} \mathrm{p}<0.05$, $* \mathrm{p}<0.1$

In cases where regime durability also affects national or ethnic identity, I may catch the effect of strengthening of ethnic cultural norms instead of people's perception of political regime durability. For example, if an adverse shock to durability increases peoples ethnic identity relative to their national identity, they may be more likely to follow their cultural traditions of FGM and thus my coefficient will be upward-biased. Indeed, Ananyev and Poyker (2018) show that civil conflict in Mali adversely affected people's national identity. I have already shown that the results are robust to inclusion of proxies for conflict; here, I show that regime durability does not correlate with ethnic identity.

To test this alternative explanation, I can't directly control on ethnic identity because DHS and MICS do not collect these data. Instead, I use data from Afrobarometer that contains information regarding people's ethnic and national identity. In particular, I use data from the 4th, 5th, and 6th waves of Afrobarometer to construct a share of people who 
B.13 Regime Durability and Ethnic Identity Online Appendix - Not for Publication identify with their ethnic group more than with the nation. ${ }^{45}$ I construct a country-year panel dataset that contains the share of people who think about themselves as members of their ethnic group rather than of the nation. To test whether regime durability is correlated with ethnic identity, I estimate the following OLS specification:

$$
\text { Ethnic Identity }_{c t}=\alpha+\delta \text { Durabilty }_{c t}+\Gamma \mathbb{X}_{c t}+\lambda_{t}+\eta_{c t}
$$

where Ethnic Identity ${ }_{c t}$ is the share of respondents in country $c$ in year $t$ who identify with their ethnic identity more than with their national identity; matrix $\mathbb{X}_{c t}$ is a set of institutional controls for Polity score and executive constraints, and $\lambda_{t}$ represents time fixed effects. ${ }^{46}$

The results are presented in Table B.12. Column I shows that durability is not correlated with ethnic identity, suggesting that durability is unlikely to affect FGM through reawakening ethnic traditions. Similarly, in Column II, I also show that durability is not associated with religiosity and thus should not affect FGM through religious beliefs.

\footnotetext{
${ }^{45}$ Questions in Afrobarometer vary from wave to wave, so the number of observations for the dependent variables in this section varies accordingly.

${ }^{46}$ I have only a few observations, so I don't add many controls in the regression. However, my results hold if I add a different set of institutional or economic controls.
} 
Online Appendix - Not for Publication

C Tables

Table C.1: List of the Samples Used in the Paper

\begin{tabular}{|c|c|c|c|c|}
\hline$\#$ & Country & DHS & MICS & $\begin{array}{c}\text { Year of FGM } \\
\text { Prohibition }\end{array}$ \\
\hline 1 & Benin & $2001,2006,2011-12$ & & 2003 \\
\hline 2 & Burkina Faso & 1998, 2003, 2010 & & 1996 \\
\hline 3 & Central African Republic & 1994-95 & 2010 & 1966 \\
\hline 4 & Cameroon & 2004 & & - \\
\hline 5 & Chad & 2004 & 2010 & 2003 \\
\hline 6 & Côte d'Ivoire & 1994, 1998, 2011-12 & & 1998 \\
\hline 7 & Egypt & $1995,2005,2008,2014$ & & 2008 \\
\hline 8 & Gambia & 2013 & & 2015 \\
\hline 9 & Ghana & & 2010-11 (Accra), 2011 & 1994 \\
\hline 10 & Guinea & 1999, 2005, 2012 & & 1965 \\
\hline 11 & Iraq & & 2011 & 2011 \\
\hline 12 & Kenya & $1998,2008-09$ & & 2001 \\
\hline 13 & Mali & $1995-96,2001,2006,2012-13$ & & - \\
\hline 14 & Mauritania & $2000-01$ & 2011 & 2005 \\
\hline 15 & Niger & 1998, 2006, 2012 & & 2003 \\
\hline 16 & Nigeria & $1999,2003,2008,2013$ & 2011 & $1994^{47}$ \\
\hline 17 & Senegal & 2005, 2010-11, 2014 & & 1999 \\
\hline 18 & Sierra Leone & 2008,2013 & 2010 & - \\
\hline 19 & Somalia $^{48}$ & & 2011 & 2012 \\
\hline 20 & Tanzania & $1996,2004,2010$ & & 1968 \\
\hline 21 & Togo & 2013-14 & 2010 & 1998 \\
\hline 22 & Yemen $^{49}$ & 2013 & & 2001 \\
\hline
\end{tabular}

Sources: Rahman and Toubia (2000), UNICEF (2013), and Ras-Work (2015).

\footnotetext{
${ }^{47}$ State-level legislation was introduced in 1999-2002.

${ }^{48}$ Northeastern zone and Somaliland.

${ }^{49}$ Before 1990, Yemen is considered as two separate states: Yemen Arab Republic and People's Democratic Republic of Yemen.
} 
Online Appendix - Not for Publication Table C.2: Summary Statistics

\begin{tabular}{llllll}
\hline Variable & Obs & Mean & Std. Dev. & Min & Max \\
\hline \hline FGM & 607648 & 0.426 & 0.494 & 0 & 1 \\
Age of FGM & 258747 & 6.054 & 5.275 & 0 & 30 \\
Age & 607648 & 28.78 & 9.404 & 10 & 49 \\
Total years of schooling & 607648 & 4.937 & 5.310 & 0 & 25 \\
Age at marriage & 474611 & 17.987 & 4.294 & 0 & 49 \\
Ever married & 607648 & 0.784 & 0.411 & 0 & 1 \\
Rural & 607648 & 0.609 & 0.488 & 0 & 1 \\
Number of children ever born & 607648 & 2.976 & 2.862 & 0 & 29 \\
Public opinion for continuation of FGM & 607648 & 0.580 & 0.255 & 0.032 & 1 \\
If thinks FGM should not continue & 607648 & 0.428 & 0.495 & 0 & 1 \\
Wealth Index & 607648 & 0.265 & 0.278 & -1 & 1 \\
Ethnicities & 607648 & & & 1 & 217 \\
Regions & 607648 & & & 1 & 326 \\
Catholic & 607648 & 0.0893 & 0.2852 & 0 & 1 \\
Muslim & 607648 & 0.5235 & 0.4994 & 0 & 1 \\
No religion & 607648 & 0.0163 & 0.1270 & 0 & 1 \\
Other religion & 607648 & 0.2043 & 0.4031 & 0 & 1 \\
Other Christians & 607648 & 0.0810 & 0.2729 & 0 & 1 \\
Protestants & 607648 & 0.0614 & 0.2401 & 0 & 1 \\
Indigenous Beliefs & 607648 & 0.0238 & 0.1525 & 0 & 1 \\
\hline \hline
\end{tabular}

Sources: DHS, MICS. 
Online Appendix - Not for Publication Table C.3: Correlation of Regime Durability with Potential Institutional Confounders

\begin{tabular}{|c|c|c|c|c|c|c|c|c|c|c|c|}
\hline & Durability & $\begin{array}{l}\text { Democracy } \\
\text { (Polity IV) }\end{array}$ & $\begin{array}{l}\text { Weighted } \\
\text { conflict } \\
\text { measure }\end{array}$ & $\begin{array}{c}\text { Anti-gov. } \\
\text { demonstrations }\end{array}$ & Civil war & $\begin{array}{c}\text { International } \\
\text { war }\end{array}$ & Gov. crisis & $\begin{array}{l}\text { Guerrilla } \\
\text { warfare }\end{array}$ & Revolution & $\begin{array}{c}\text { Political } \\
\text { assasinations }\end{array}$ & $\begin{array}{c}\text { General } \\
\text { strikes }\end{array}$ \\
\hline Durability & 1 & & & & & & & & & & \\
\hline Democracy (Polity IV) & -0.18 & 1 & & & & & & & & & \\
\hline Weighted conflict measure & 0.02 & -0.08 & 1 & & & & & & & & \\
\hline Anti-gov. demonstrations & -0.02 & 0.00 & 0.29 & 1 & & & & & & & \\
\hline Civil war & 0.01 & -0.03 & 0.44 & 0.07 & 1 & & & & & & \\
\hline International war & 0.26 & -0.06 & 0.04 & 0.03 & 0.07 & 1 & & & & & \\
\hline Gov. crisis & 0.02 & 0.01 & 0.35 & 0.28 & 0.19 & 0.08 & 1 & & & & \\
\hline Guerrilla warfare & 0.03 & -0.09 & 0.68 & 0.04 & 0.37 & 0.08 & 0.12 & 1 & & & \\
\hline Revolution & 0.01 & -0.06 & 0.90 & 0.15 & 0.38 & 0.02 & 0.25 & 0.39 & 1 & & \\
\hline Political assasinations & 0.09 & -0.06 & 0.21 & 0.08 & 0.04 & -0.03 & 0.09 & 0.09 & 0.10 & 1 & \\
\hline General strikes & -0.03 & 0.03 & 0.19 & 0.35 & 0.00 & 0.00 & 0.14 & 0.03 & 0.09 & 0.06 & 1 \\
\hline
\end{tabular}

Notes: Durability and democracy are from the Polity IV dataset. Other variables are from Banks and Wilson (2016). 
Online Appendix - Not for Publication

D Figures

Figure D.1: Historical Boundaries of Ethnicities before Colonization and FGM Prevalence

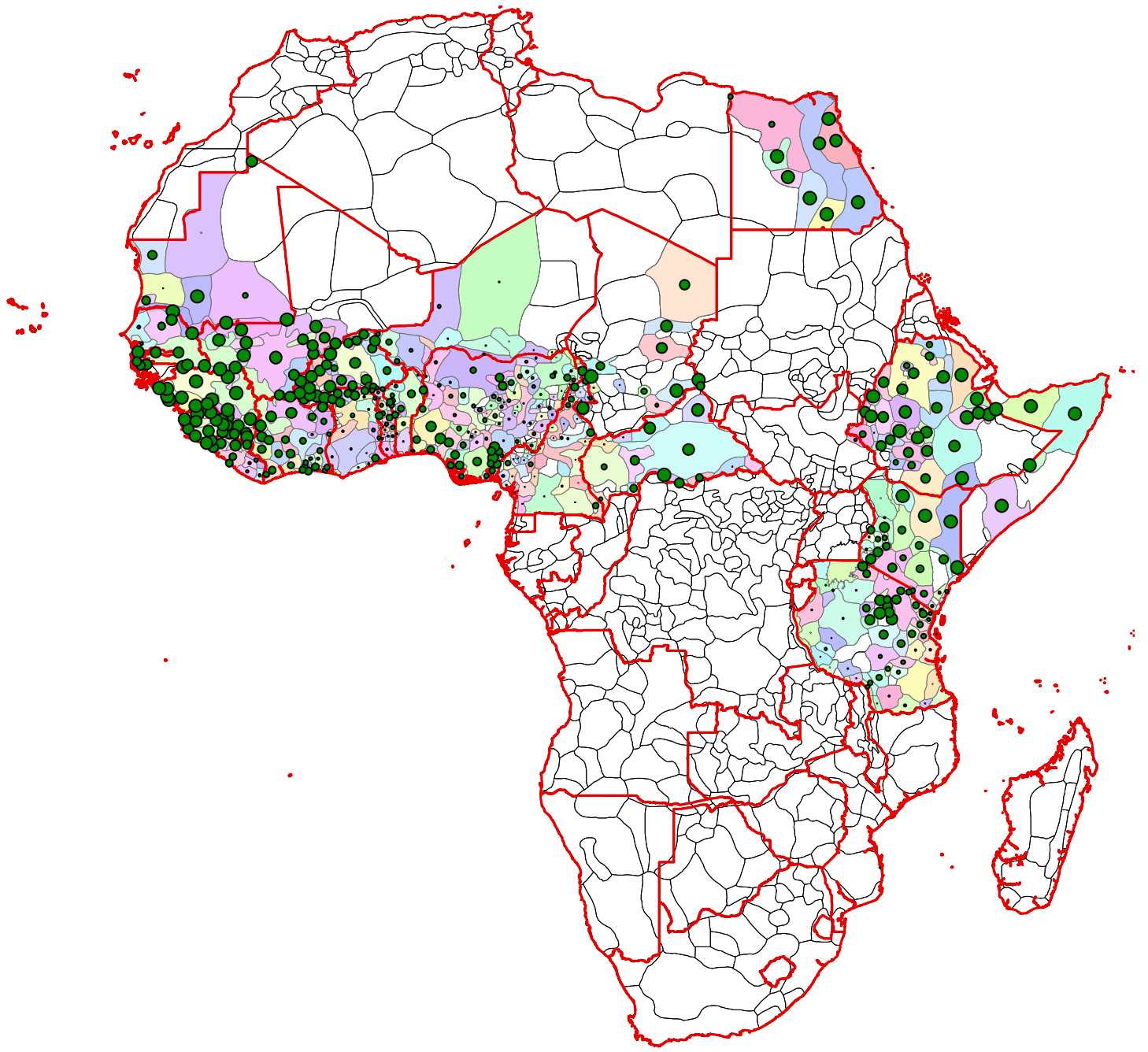

Notes: Black boundaries represent ethnic groups' borders according to Murdock (1959). Red lines represent countries' borders. Colored regions represent ethnic groups in the DHS and MICS data. Data for Sudan, South Sudan, and Uganda are not available. Other African countries have FGM rates close to zero. FGM rates: latest available DHS surveys with GPS coordinates and FGM questionnaire. The data for Mauritania and Somalia are taken from MICS. FGM rates for Chad, Gambia, Mauritania, and Somalia are merged to Murdock (1959) map by using questions about the ethnic group of the respondent. 
Online Appendix - Not for Publication

Figure D.2: Map of Shares of Circumcised Women by Country

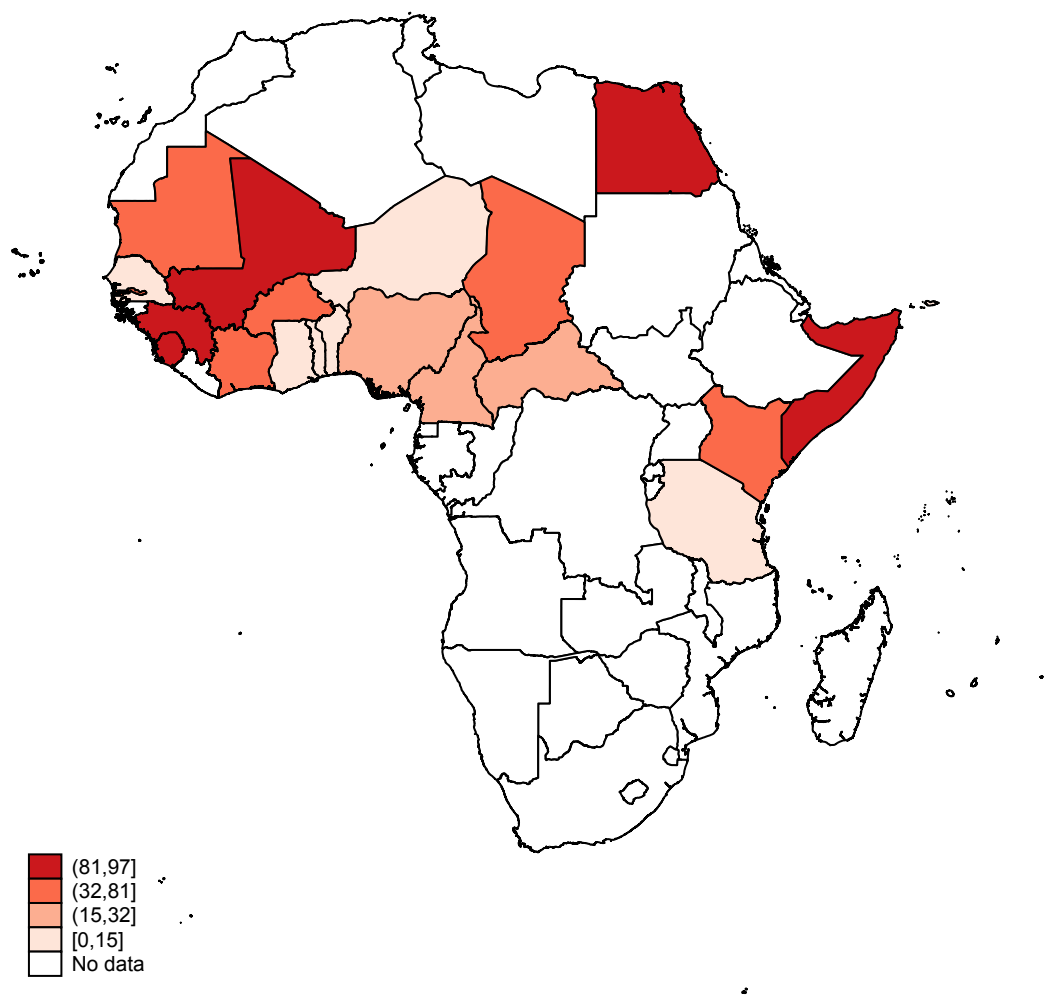

Notes: Averaged FGM rates (with red color) across all African surveys used in the paper. 
Online Appendix - Not for Publication

Figure D.3: Cumulative Distribution of FGM Age for the Akan and Guerze Ethnicities
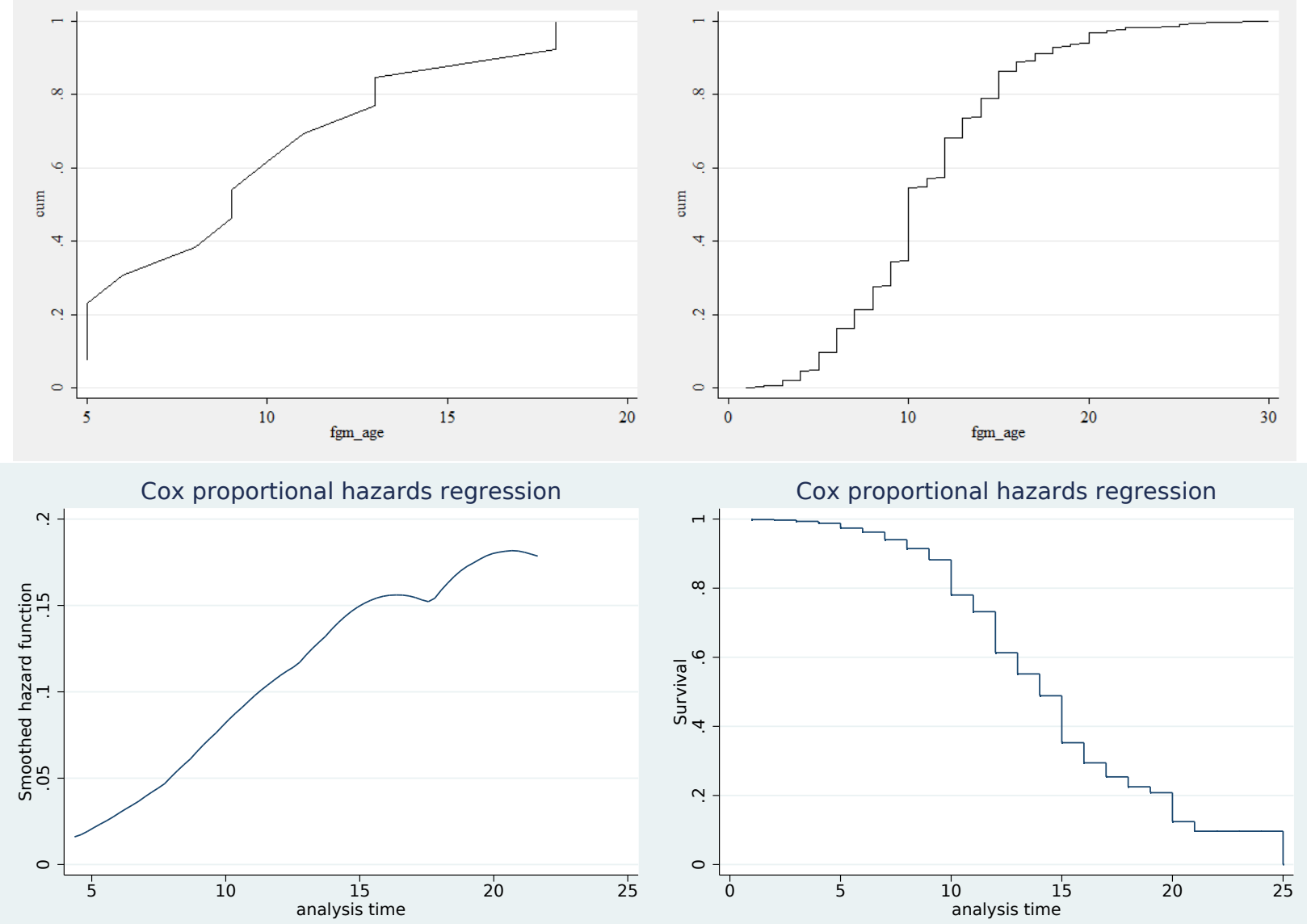

Note: Hazard and survival functions are estimated on a subsample of women who have undergone circumcision. 
Online Appendix - Not for Publication

Figure D.4: Density and Cumulative Distribution of Age, and FGM Age

Panel A

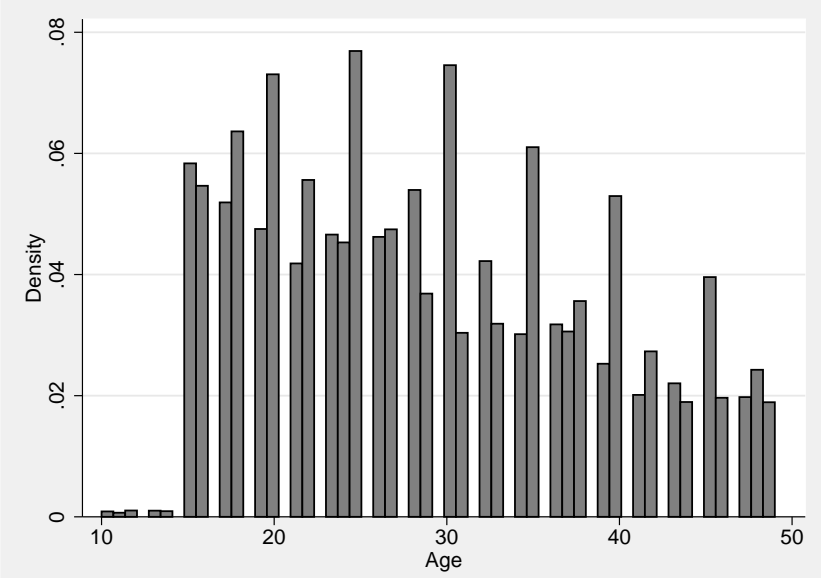

Panel B

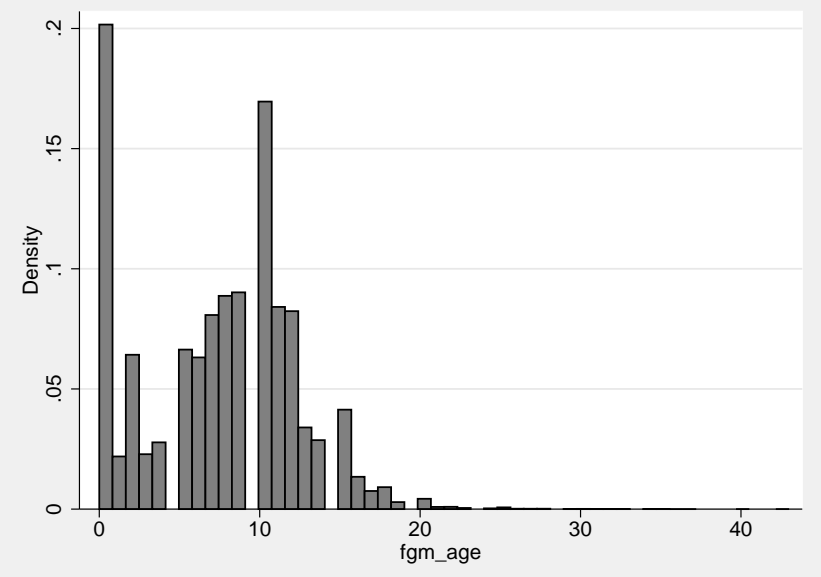

Panel C

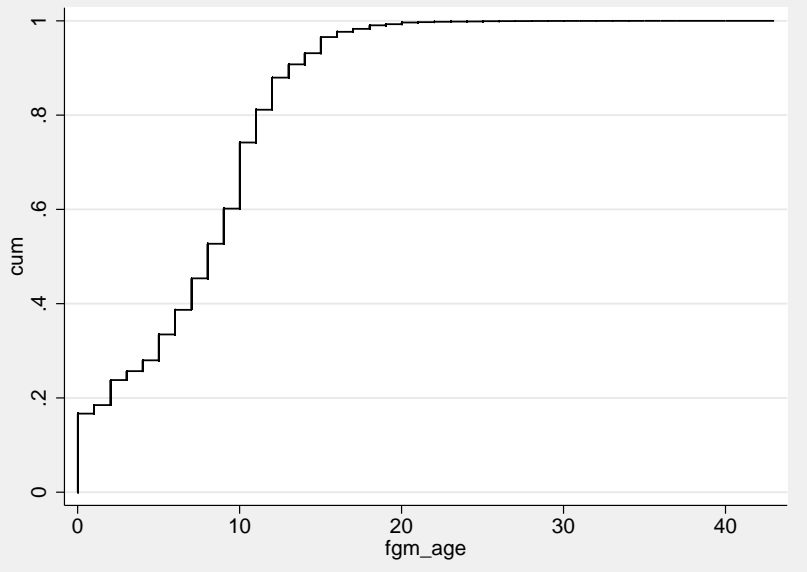

Note: Based on all surveys used in the paper (see Table C.1). 
Online Appendix - Not for Publication Figure D.5: Historical Boundaries of Ethnicities before Colonization and Countries' Regional Administrative Division.

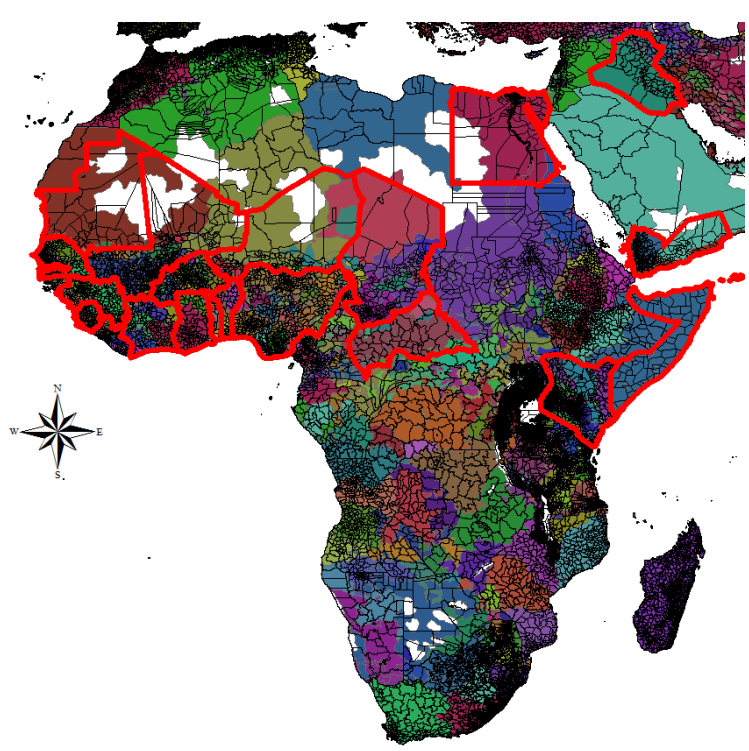

Notes: Black boundaries represent regional administrative borders groups' borders according to Global Administrative Areas (www. gadm. org/). Red lines represent borders of the countries in my sample. Colored regions represent ethnic groups in the DHS and MICS data. 


\section{References}

Acemoglu, Daron, and Simon Johnson. 2005. "Unbundling institutions." Journal of political economy, 113(5): 949-995.

Acemoglu, Daron, Suresh Naidu, Pascual Restrepo, and James A Robinson. 2014. "Democracy does cause growth." National Bureau of Economic Research.

Altonji, Joseph G, Todd E Elder, and Christopher R Taber. 2005. "Selection on Observed and Unobserved Variables: Assessing the Effectiveness of Catholic Schools." Journal of Political Economy, 113(1).

Ananyev, Maxim, and Michael Poyker. 2018. "State Capacity and Demand for Identity: Theory and Evidence from Political Instability in Mali."

Banks, Arthur S, and Kenneth A Wilson. 2016. "Cross-National Time-Series Data Archive. Databanks International."

Beck, Nathaniel, Jonathan N Katz, and Richard Tucker. 1998. "Taking time seriously: Time-series-cross-section analysis with a binary dependent variable." American Journal of Political Science, 1260-1288.

Besley, Timothy, and Torsten Persson. 2011. Pillars of prosperity: The political economics of development clusters. Princeton University Press.

Blundell, Richard, and Stephen Bond. 1998. "Initial conditions and moment restrictions in dynamic panel data models." Journal of econometrics, 87(1): 115-143.

Burbidge, John B, Lonnie Magee, and A Leslie Robb. 1988. "Alternative transformations to handle extreme values of the dependent variable." Journal of the American Statistical Association, 83(401): 123-127.

Burke, Marshall, Erick Gong, and Kelly Jones. 2015. "Income Shocks and HIV in Africa." The Economic Journal, 125(585): 1157-1189.

Camilotti, Giulia. 2015. "Interventions to Stop Female Genital Cutting and the Evolution of the Custom: Evidence on Age at Cutting in Senegal." Journal of African Economies, $4-13$.

Chamberlain, Gary. 1980. "Analysis of Covariance with Qualitative Data." The Review of Economic Studies, 47(1): 225-238.

Cheibub, José Antonio, Jennifer Gandhi, and James Raymond Vreeland. 2010. “Democracy and dictatorship revisited." Public Choice, 143(1-2): 67-101.

Feenstra, Robert C, Robert Inklaar, and Marcel Timmer. 2015. “The Next Generation of the Penn World Table." American Economic Review. 
Freedom House. 2013. "Freedom in the World 2013." Democratic breakthroughs in the balance.

Geddes, Barbara, Joseph Wright, and Erica Frantz. 2014. "Autocratic breakdown and regime transitions: A new data set." Perspectives on Politics, 12(02): 313-331.

Goemans, Henk E, Kristian Skrede Gleditsch, and Giacomo Chiozza. 2009. "Introducing Archigos: A dataset of political leaders." Journal of Peace research, 46(2): 269-283.

GTD. 2015. National Consortium for the Study of Terrorism and Responses to Terrorism (START). Global Terrorism Database [Data file]. Retrieved from www.start.umd.edu/gtd.

Honoré, Bo E, and Adriana Lleras-Muney. 2006. "Bounds in competing risks models and the war on cancer." Econometrica, 74(6): 1675-1698.

Mackie, Gerry, and John LeJeune. 2009. "Social dynamics of abandonment of harmful practices: a new look at the theory." Special series on social norms and harmful practices, 2009-06.

Marshall, Monty G., and Benjamin R. Cole. 2013. "Polity IV data set and codebook. Available at www.systemicpeace.org/polity/polity4.htm (accessed 21 March 2015)."

Murdock, George P. 1959. "Africa: its peoples and their culture history."

Oster, Emily. 2017. "Unobservable selection and coefficient stability: Theory and evidence." Journal of Business \& Economic Statistics, 1-18.

Rahman, Anika, and Nahid Toubia. 2000. Female Genital Mutilation: A practical guide to worldwide laws \& policies. Zed Books.

Ras-Work, B. 2015. “Legislation to Address the Issue of Female Genital Mutilation (FGM): Expert Group Meeting on good practices in legislation to address harmful practices against women."

Sarkees, Meredith Reid, and Frank Wayman. 2010. "Resort to War: 1816 - 2007."

UNICEF. 2013. "Female Genital Mutilation/Cutting: a statistical overview and exploration of the dynamics of change." UNICEF.

Venkataramani, Atheendar S, and Brendan Maughan-Brown. 2013. "Effects of household shocks and poverty on the timing of traditional male circumcision and HIV risk in South Africa." AIDS and Behavior, 17(5): 1668-1674.

World Bank Group. 2016. World Development Indicators. World Bank Publications. 